\title{
Diagnosis of High Voltage Insulators Made of Ceramic Using Spectrophotometry
}

\author{
Paweł Frącz, Ireneusz Urbaniec, Tomasz Turba, and Sławomir Krzewiński
}

Faculty of Electrical Engineering, Automatic Control and Computer Science, Opole University of Technology, Prószkowska 76, 45-758 Opole, Poland

Correspondence should be addressed to Paweł Frącz; pawelfracz2@gmail.com

Received 5 April 2016; Revised 22 June 2016; Accepted 30 June 2016

Academic Editor: Jau-Wern Chiou

Copyright (C) 2016 Paweł Frącz et al. This is an open access article distributed under the Creative Commons Attribution License, which permits unrestricted use, distribution, and reproduction in any medium, provided the original work is properly cited.

The paper presents results of comparative analysis of optical signals emitted by partial discharges occurring on three types of high voltage insulators made of porcelain. The research work consisted of diagnosis of the following devices: a long rod insulator, a cap insulator, and an insulating cylinder. For optical signal registration a spectrophotometer was applied. All measurements were performed under laboratory conditions by changing the value of partial discharges generation voltage. For the cylindrical insulator also the distance between high voltage and ground electrodes was subjected for investigation as a factor having influence on partial discharges. The main contribution which resulted from the studies is statement that application of spectrophotometer enables faster recognition of partial discharges, as compared to standard methods.

\section{Introduction}

This research concerns a field of science which is related to the generation and development of electric discharges on surfaces of high voltage (HV) insulation systems. An important problem of insulation systems is the ageing process progressing during their operation and causing deterioration of insulating properties [1-3]. Important ageing factors that occur in operational practice include UV radiation, ozone and nitrogen oxides, temperature fluctuations, rainfall (including acid rain), rime deposition, dirt, and partial discharges (PD). The origin of research and scientific studies conducted by our team is the need to analyze the physical phenomena that occur during electric discharges on the surface on nonorganic (ceramic) dielectrics. The main objective of research conducted within this scope is to determine as accurately as possible how, when, and at what pace a process of deterioration of insulation elements is progressing. Another issue is to determine the conditions under which the complete breakdown occurs. The studies involved measurements of optical emission spectra of electric discharges occurring on the surface of ceramic insulation using spectrophotometer. Based on the gathered data, the initial voltage values of electric discharges $U_{10}$ were estimated with a greater sensitivity and faster than previously possible, based on the measurement of initial corona voltage $U_{0}$. The presented study results were aimed at confirming the hypothesis that measurement of emission spectra, especially in the range from $250 \mathrm{~nm}$ to $280 \mathrm{~nm}$, generated by electric discharges occurring on surfaces of ceramic dielectrics, can serve as a sensitive and effective indicator of their surface strength.

\section{Materials and Methods}

2.1. Metrological Parameters of the Measuring System. Nowadays, there are many measurement methods of detecting $\mathrm{PD}$ occurring in the insulating systems of electrical power equipment. Diagnostic methods can be divided into invasive methods and noninvasive methods. Invasive methods involve detection and recording PD currents using special measuring probes that express $\mathrm{PD}$ value in $\mathrm{pC}$. The disadvantage of such methods is the need to disconnect the tested device from the power supply during connection and disconnection of the measuring apparatus [4-6]. Alternative methods do not require invasion in the operation of the device, making them safer for people performing measurements with measuring equipment, usually hand-held and portable $[7,8]$. 
The acoustic method allows the detection of ultrasound (sound pressure) within the range of up to $500 \mathrm{kHz}$ generated in the early stage of surface PD using the specialized devices $[9,10]$. The electromagnetic method, depending on the instrument used, allows the recording of the intensity of spectrum for varying radiation range. The knowledge available today in the literature allowed us to conclude that the emitted spectrum is in the range from ultraviolet to infrared radiation $[11,12]$ and in X-rays in the range $10 \mathrm{pm}$ to $10 \mathrm{~nm}$ [13].

This paper concerns electromagnetic method, and particularly recording of UV and visible radiation. The properties of electromagnetic radiation emitted during the PD depend on the type of insulating material and parameters of the propagation medium and the environment surrounding the area of PD generation, such as pressure, temperature, and humidity $[14,15]$.

The basic technique for measuring optical radiation is spectrophotometry. Its main advantage is the galvanic separation of the measuring position from the tested device, which is under high voltage [16]. Thanks to that, the obtained results do not affect external electromagnetic fields with high intensity and other types of disturbances that have negative impact on the signals recorded using electric or acoustic method. A condition necessary for the detection of PD with the use of optical method is a direct line of sight. A method for recording optical radiation is the spectrophotometry technique, allowing the recording of not only the radiation intensity but, above all, the occurrence and shape of the spectrum present in the emitted signals [17]. In this technique spectrophotometers are used, which are currently being constructed from sets of photodiodes with variable wavelengths, light-sensitive CCD detectors, and special software for processing $[18,19]$. An important parameter affecting the accuracy and efficiency of the obtained results of measurements is the amount of attenuation and dispersion of optical signals depending, among other things, on the distance of the recording equipment from the point of $\mathrm{PD}$ generation and the propagation medium itself.

Table 1 presents basic technical parameters of the Ocean Optics HR4000 spectrophotometer used in the measurements. Measurement data archiving and processing were performed using numerical procedures implemented in the MATLAB programming environment.

All the measurements were conducted in a darkened room of the laboratory. The measurement procedure included increase of the PD generation voltage from 0 to $100 \mathrm{kV}$ while recording the intensity of optical radiation. For each of the considered voltage levels, five measurements using a spectrophotometer were made. The power supply system consisted of a testing transformer and a control panel, which included an autotransformer, an overcurrent protection system, and a voltmeter for measurement of the momentary voltage value. The voltage values were controlled by the autotransformer and forwarded to primary winding of the single-phase testing transformer. The output of the secondary winding was connected to a water resistor for limitation of the short-circuit current with which the tested insulator was powered.
TABLE 1: Characteristics of technical parameters of spectrophotometer applied in the study.

\begin{tabular}{|c|c|c|}
\hline Parameter & Value & Unit \\
\hline CCD detector & Toshiba TCS1304AP - 3648 & Pixel \\
\hline $\begin{array}{l}\text { Integration time } \\
\text { (counting time) }\end{array}$ & from $3.8 \times 10^{-3}$ to 20 & $\mathrm{~s}$ \\
\hline Type of optical link & SMA 905 & \\
\hline $\begin{array}{l}\text { Width of apertures } \\
\text { lit }\end{array}$ & $5,10,25,50,100,200$ & $\mu \mathrm{m}$ \\
\hline Optical resolution & $\sim 0.02-8.4$ & nm FWHM \\
\hline Light scattering & $<0.05 \%$ for $600 ;<0.1 \%$ for 435 & $\mathrm{~nm}$ \\
\hline Visible light range & $190-1100$ & $\mathrm{~nm}$ \\
\hline UV spectral range & $200-1100$ & $\mathrm{~nm}$ \\
\hline Dynamic range & $1300: 1$ & \\
\hline Corrected linearity & $>99.8$ & $\%$ \\
\hline $\mathrm{A} / \mathrm{D}$ resolution & 14 & bits \\
\hline $\begin{array}{l}\text { Maximum pixel } \\
\text { digitalization range }\end{array}$ & 1 & $\mathrm{MHz}$ \\
\hline $\begin{array}{l}\text { Size of pixel, CCD } \\
\text { element }\end{array}$ & $8 \times 200$ & $\mu \mathrm{m}$ \\
\hline Sensitivity & 100 per count for $800 \mathrm{~nm}$ & Photons \\
\hline
\end{tabular}

Measurement cycles were conducted for supply voltage varying in the range from initial voltages $U_{0}$ to $U_{p}$. The initial voltages $U_{0}$ and $U_{01}$ were determined based on voltmeter reading, while the spectrophotometer showed intensity exceeding 300 .

The breakdown voltage depended on the type of tested porcelain and the distance between electrodes. An optical transducer was placed in a specially designed holder mounted on a stand, allowing us to adjust height, angle, and distance between the measuring head and the area of PD occurrence on the tested dielectric. For each tested dielectric, a value of initial voltage $U_{0}$ and a breakdown voltage $U_{p}$ was determined five times prior to the measurement of PD. Measurements of emission spectra were conducted for averaged values relative to $U_{0}$ and $U_{p}$.

The tests involved the preparation of three ceramic insulation systems for PD generation, that is,

(i) LS-type long rod insulator (Figure 1(a)),

(ii) WPK-type porcelain cylinder, filled with quartz (Figure 2(b)),

(iii) LK-type cap insulator (Figure 2(a)).

For the WPK-type insulator, PD measurements were performed at various distances between the HV and ground electrodes in the range from $3 \mathrm{~cm}$ to $11 \mathrm{~cm}$. In consequence, the following definitions are used in this paper: WPK3, WPK5, WPK7, WPK9, and WPK11, where the numbers correspond to the distance between electrodes in $\mathrm{cm}$.

2.2. Numerical Methods Applied for Measurement Results Analysis. The obtained results of measurements of emission spectra were analyzed statistically in order to determine differences and similarities between signals and to determine 


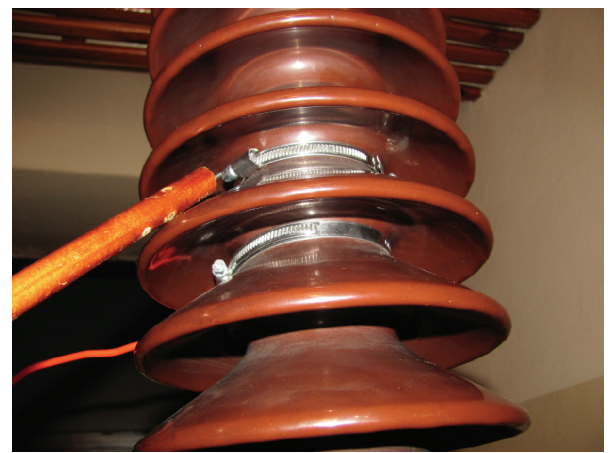

(a)

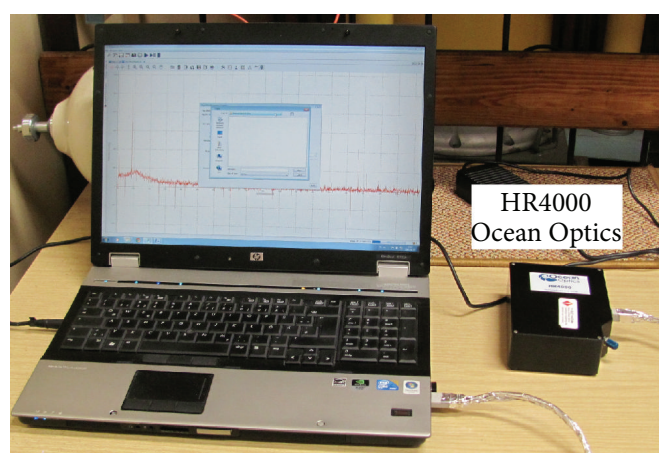

(b)

Figure 1: (a) The long rod insulator, type LS, and (b) the spectrophotometer applied in the study.

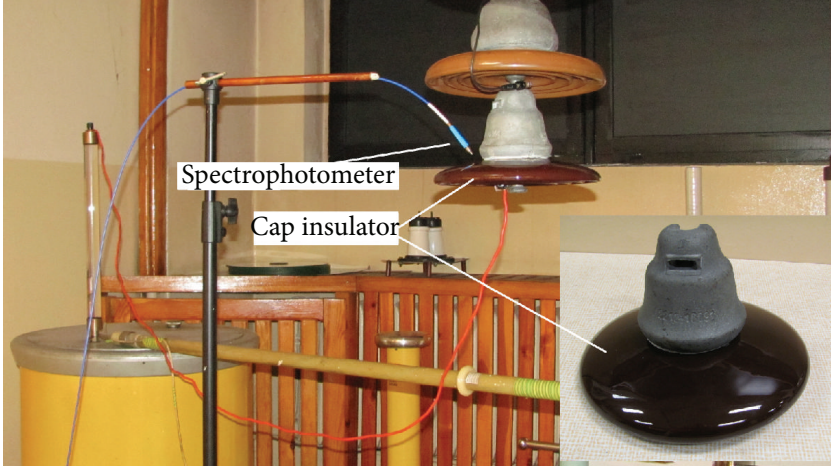

(a)

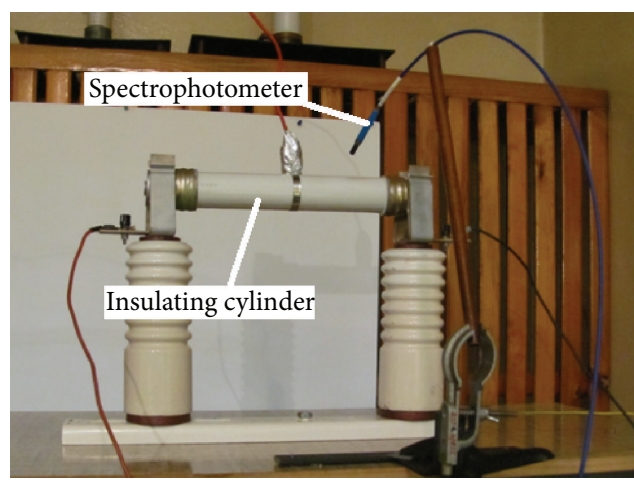

(b)

FIGURE 2: (a) The cap insulator, type LK, and (b) the cylindrical insulator, type WPK.

the effect of PD generation voltage on the obtained emission spectra. Light emission intensity spectra were visualized for various PD generation voltages, as well as using cumulative graph for all tested voltages. Histograms showing the number of variable intensity radiation $I$ were calculated for individual wavelengths. A histogram is a graphical method to present the empirical distribution, which is determined by calculating the frequency distribution. Histograms were presented on cumulative graphs showing the dependence of obtained values on $\mathrm{PD}$ generation voltage. Wavelength ranges were determined for the light emission of the highest intensity. These values are dependent on the voltage of PD generation and the type of studied insulation system. Recorded characteristics underwent a process of mathematical regression. For that, components of linear spectrum were determined using a series of Gaussian functions. The developed procedures use Nelder-Mead Simplex method to look for optimal parameters of the function in question, that is, parameters that would provide minimum deviations between theoretical and empirical data (3). A final effect was the sum of spectral components in the form of relation designated as M2

$$
\operatorname{M} 2(\lambda)=\sum_{i=1}^{N} A_{i} * e^{-\left(\left(\lambda-B_{i}\right) / C_{i}\right)^{2}},
$$

where $\lambda$ is independent variable wavelength, $A_{i}$ is amplitude of component (spectral line) of width $C_{i}, N$ is varying number of components in the model, and $A, B$, and $C$ are model parameters.

In order to determine most predominant components of the linear spectrum, a mathematical model M1 was developed that can be described using relation (2). M1 model is a sum of eight Gaussian functions:

$$
\operatorname{M1}(\lambda)=\sum_{i=1}^{8} A_{i} * e^{-\left(\left(\lambda-B_{i}\right) / C_{i}\right)^{2}},
$$

where $\lambda$ is independent variable wavelength, $A_{i}$ is amplitude of component (spectral line) of width $C_{i}$, and $A, B$, and $C$ are model parameters:

$$
\delta=\sqrt{\sum_{\forall i}\left(x_{i}-\tilde{x}_{i}\right)^{2}}
$$

where $x_{i}$ is $i$ th empirical variable value and $\tilde{x}_{i}$ is $i$ th theoretical variable value (estimated).

In order to perform analysis of obtained regression results, values of coefficients which are the measures of matching the studied models to the studied dependence were 


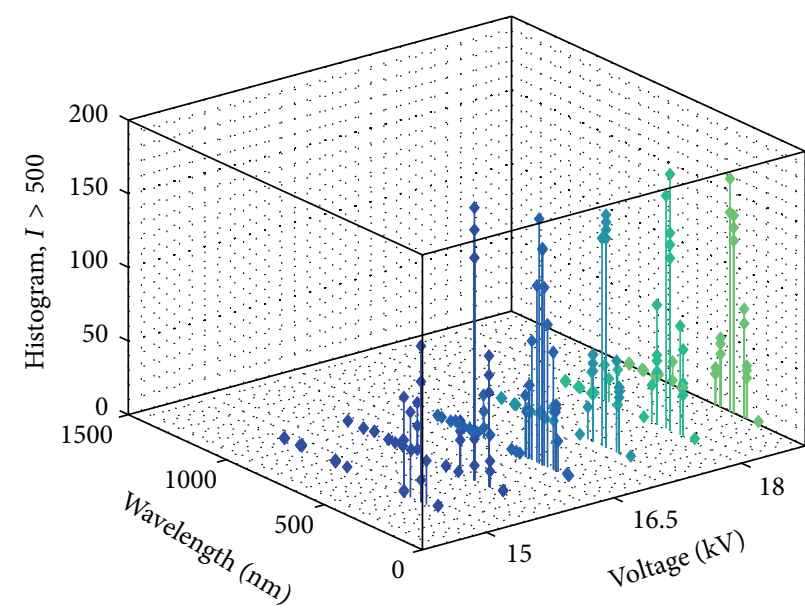

(a)

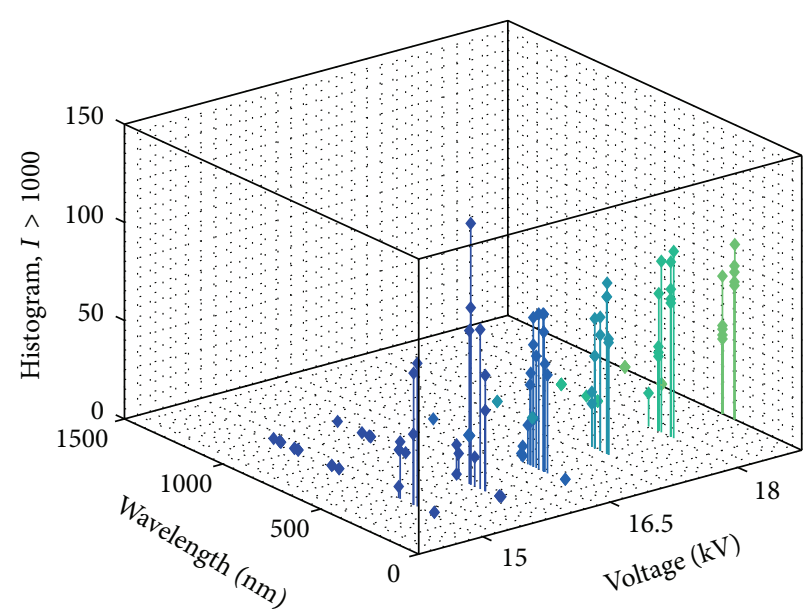

(b)

FIGURE 3: Summary of spectrum intensity histograms for different voltages: (a) $I>500$ and (b) $I>1000$.

determined, including SSE (4), RMSE (5), $R$-square (6), and adj- $R$-square (7).

(a) SSE is the sum of squares of residuals. It determines the total deviation of estimated values from empirical data. A value close to zero indicates that the model has a smaller random error component, and the fitting can be more useful for prediction:

$$
\operatorname{SSE}=\sum_{\forall i}\left(y_{i}-\tilde{y}_{i}\right)^{2},
$$

where $y_{i}$ is $i$ th empirical variable value and $\tilde{y}_{i}$ is $i$ th theoretical variable value (estimated).

(b) RMSE is the standard error of regression constituting the root mean square error. The value close to one means higher utility of the considered model for prediction:

$$
\text { RMSE }=\sqrt{\frac{\sum_{\forall i}\left(y_{i}-\tilde{y}_{i}\right)^{2}}{n-p}},
$$

where $y_{i}$ is $i$ th empirical variable value, $\tilde{y}_{i}$ is $i$ th theoretical variable value (estimated), $n$ is number of samples contained in estimated course/dependence, and $p$ is number of model parameters.

(c) $R$-square $\left(R^{2}\right)$ determines the variability in the data. This value is the square of the correlations between empirical and estimated data. Values close to one indicate that most of the variance is included in the model. In this study, we apply $R^{2}$ as a fitting indicator. Values above 0.6 and 0.8 indicate well and very well fitting results, respectively. Values equal or less than 0.5 indicate poor or no fitting, respectively:

$$
R \text {-square }=1-\frac{\sum_{\forall i}\left(y_{i}-\tilde{y}_{i}\right)^{2}}{\sum_{\forall i}\left(y_{i}-\mu\right)^{2}},
$$

where $y_{i}$ is $i$ th empirical variable value, $\tilde{y}_{i}$ is $i$ th theoretical variable value (estimated), and $\mu$ is arithmetic mean of the empirical data. (d) Adj-R-square (adj- $R^{2}$ ) is a determination coefficient adjusted by the number of degrees of freedom. It is an indicator that allows the comparison of results obtained by models with different numbers of parameters. The values are in the range below one. Values close to one indicate a good matching of the model to empirical data. Negative values indicate that the model contains elements that do not help in predicting model response:

$$
\text { adj- } R \text {-square }=1-\frac{\operatorname{SSE}(n-1)}{\operatorname{SST}(n-p)},
$$

where $n$ is number of samples contained present in estimated curve/dependence and $p$ is number of model parameters:

$$
\mathrm{SST}=\sum_{\forall i}\left(y_{i}-\mu\right)^{2},
$$

where $y_{i}$ is $i$ th empirical variable value and $\mu$ is arithmetic mean of the empirical data.

M1 and M2 models, despite apparent similarities, are very different in terms of number of parameters and parameter estimation method. The paper presents fit coefficients calculated using regression for both models, that is, SSE, $R$-square, and RMSE in form of 3D graphs visualizing dependence as a function of $\mathrm{PD}$ generation voltage.

\section{Example Results and Discussion}

3.1. Analysis of Emission Spectra of Discharges Occurring on the Surface of Porcelain Insulation Cylinder Filled with Quartz: Example Distance between Electrodes Is $3 \mathrm{~cm}$. Figure 3 presents a cumulative comparison of histograms calculated for spectra of the highest intensities obtained during measurements as a function of PD generation value. The graph on the left refers to the intensity exceeding the value of $500(I>500)$, while the graph on the right indicates intensity exceeding the value of $1000(I>1000)$. On the basis of this analysis, it is possible to determine the frequency of light emission generated by PD for a given wavelength. 
TABLE 2: Dominant wavelengths present in light emission of value $I>1000$.

\begin{tabular}{|c|c|}
\hline $\begin{array}{l}\text { Wavelength } \\
\text { interval } \\
(\mathrm{nm})\end{array}$ & $\begin{array}{l}\text { Dominant wavelengths and intervals present } \\
\text { in light emission of value } I>1000 \\
(\mathrm{~nm})\end{array}$ \\
\hline$\lambda=[200-299$ & $203,296-298$ \\
\hline$\lambda=[300-399]$ & $\begin{array}{c}311-318,333-340,351-360,369-382 \\
390-396,397-399\end{array}$ \\
\hline$\lambda=[400-499]$ & $400-401,404-407,420,425-428,434-435$ \\
\hline$\lambda>500$ & $745,933,1073$ \\
\hline
\end{tabular}

Based on the obtained histograms for intensities of values exceeding 1000, dominant light wavelengths occurring in the recorded signals were determined for the individual intervals and presented in Table 2.

Figure 4 presents the results of modeling intensity spectra using Gaussian series, model M2 for selected values of PD generation voltage. A red color denotes measurement results, while blue denotes modeling results. The legend contains value of determination coefficient $R^{2}$.

Figures 5 and 6 present graphically the values of fitting parameters, $R^{2}$, RMSE, and SSE obtained from the regressions using Gaussian series M2 for data recorded during each of five measurements conducted for various PD generation values.

Based on the $R^{2}$ coefficient analysis, it was found that the M2 model was performed with an excellent adequacy level in the majority of cases, which was confirmed by the obtained values, close to 1 . No fitting was obtained for lower PD generation voltages. This is due to a lack of dominant wavelengths emitted by $\mathrm{PD}$ at these voltages.

Based on the analysis of the values of the coefficients RMSE and SSE that reached values above 100, it was concluded that the model should not be used for prediction.

Figure 7 presents the results of modeling intensity spectra using a sum of eight Gaussian functions, model M1 for selected values of PD generation voltage. The red color denotes measurement results and blue corresponds to modeling results. The legend contains the value of determination coefficient $R^{2}$.

Figures 8 and 9 present graphical values of fitting parameters, $R^{2}$, RMSE, and SSE obtained by the regression of model M1 for all data recorded during each five measurements conducted by different PD generation values.

It was found that the M1 model was performed in a very similar way to the M2 model with an excellent adequacy level in the majority of cases, which was confirmed by the obtained values of $R^{2}$, close to one. Only in individual cases for the lowest PD generation voltages, poor fitting or no fitting was observed.

The application of the M1 model allowed precise determination of intensity and wavelength of dominant light waves in recorded spectrum emitted by PD. Figure 9(b) presents intensity of individual wavelengths depending on the value of voltage supplying given system.

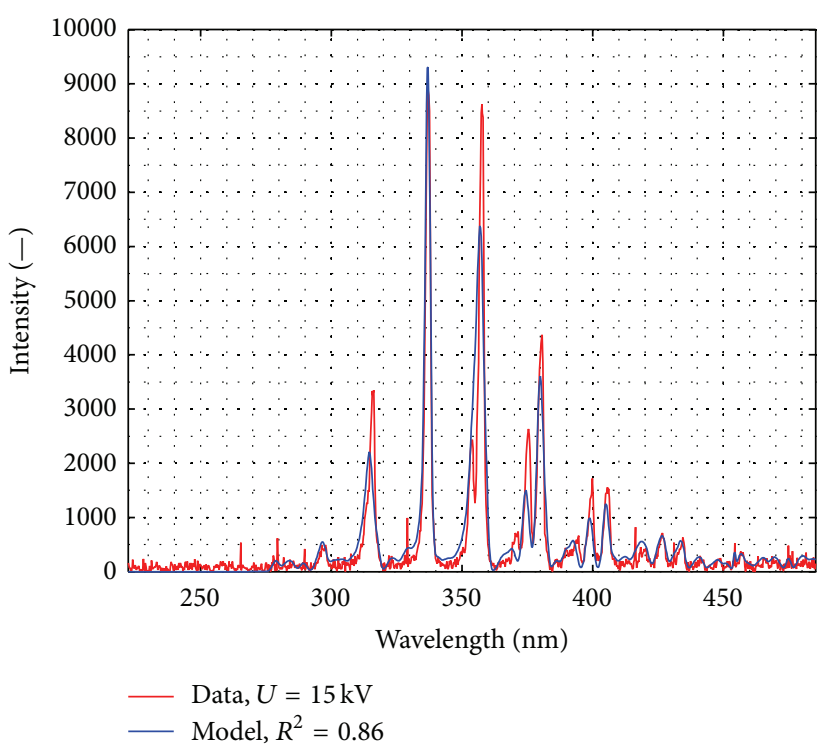

(a)

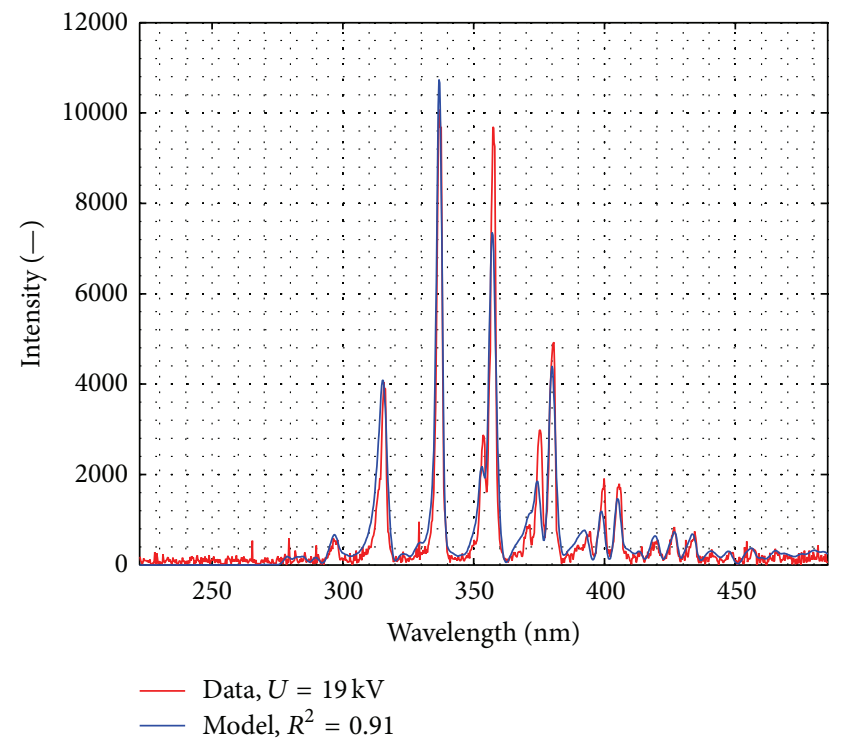

(b)

FIGURE 4: Intensity spectra of recorded and modeled light emission for selected values of PD generation voltages: (a) $0.75 U_{p}=15 \mathrm{kV}$ and (b) $0.94 U_{p}=19 \mathrm{kV}$.

3.2. Analysis of Emission Spectra of Discharges Occurring on the Surface of LK-Type Cap Insulator. Figure 10 depicts cumulative comparison of histograms calculated for spectra of highest intensities obtained during measurements as a function of PD generation value. Figure 10(a) refers to the intensity exceeding the value of $500(I>500)$ and Figure 10(b) intensity exceeding the value of $1000(I>1000)$.

For intensities of values exceeding 1000, dominant light wavelengths occurring in the recorded signals were determined for the individual intervals and presented in Table 3.

Figure 11 shows the results of modeling (blue line) intensity spectra using model M2 for selected values of PD 


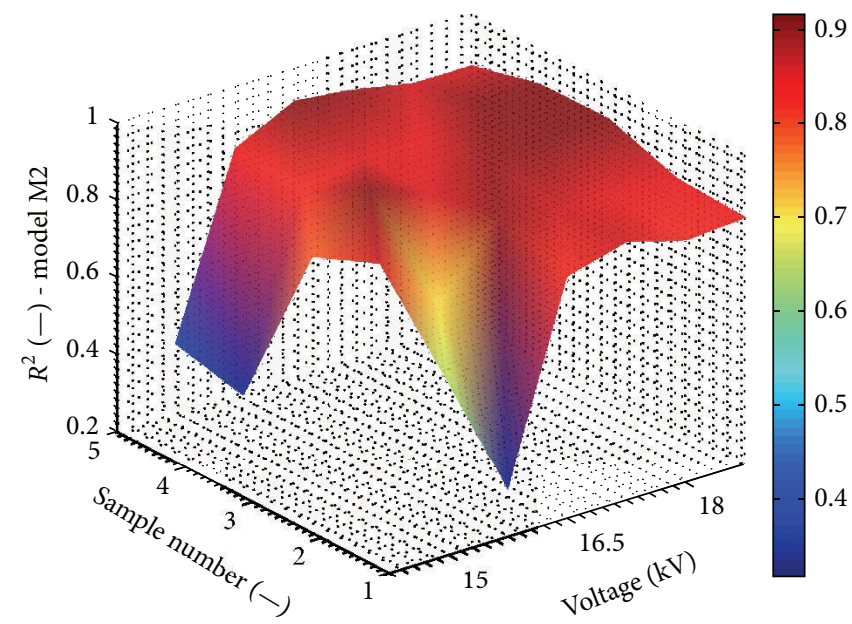

FIGURE 5: Comparison of values of $R^{2}$ coefficient obtained by the regression of the model M2 for all the recorded signals.

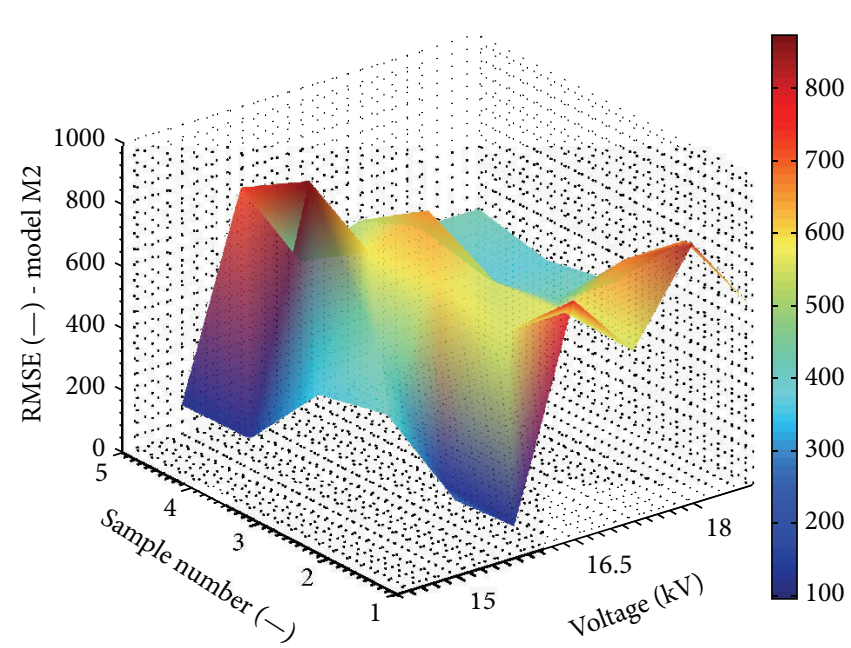

(a)

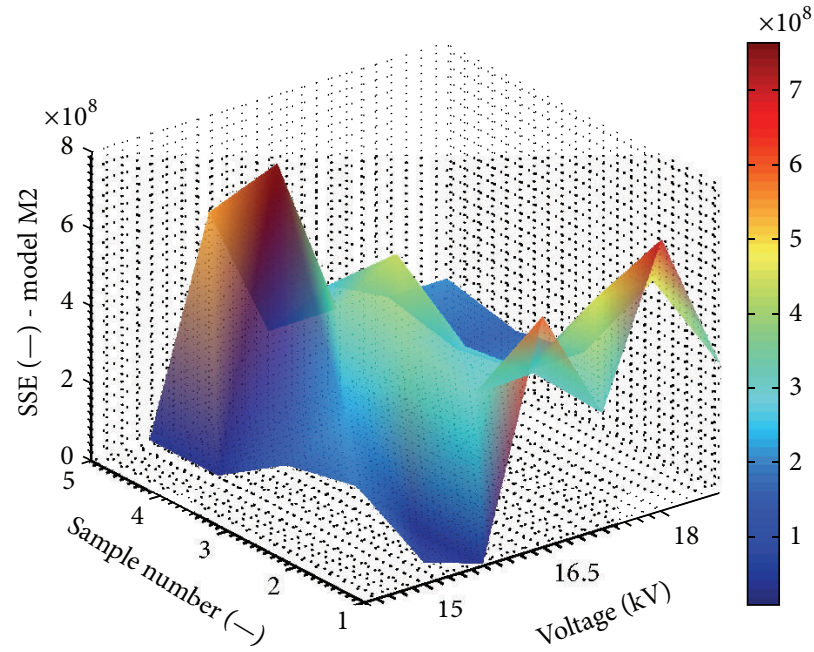

(b)

FIGURE 6: Comparison of values of coefficients RMSE (a) and SSE (b) obtained by the regression of the model M2 for all the recorded signals.

TABLE 3: Dominant wavelengths present in light emission of value $I>1000$.

\begin{tabular}{lc}
\hline $\begin{array}{l}\text { Wavelength interval } \\
(\mathrm{nm})\end{array}$ & $\begin{array}{c}\text { Dominant wavelengths and intervals for } \\
I>1000(\mathrm{~nm})\end{array}$ \\
\hline$\lambda=[200-299]$ & 243 \\
$\lambda=[300-399]$ & $312-317,329,333-339,352-371,373-382$, \\
& $398-399$ \\
$\lambda=[400-499]$ & $400,404-406,435,460$ \\
$\lambda>500$ & 724,933 \\
\hline
\end{tabular}

generation voltage compared to measurement results (red line).

Figures 12 and 13 present values of fitting parameters, $R^{2}$, RMSE, and SSE obtained from the regressions using model M2 for data recorded during each five measurements conducted by different PD generation values.
It was found that model M2 obtained an excellent adequacy level for PD generation voltage values of $60 \mathrm{kV}$ and 70-80 kV. However, no fitting was obtained for other voltages. The coefficients RMSE and SSE that reached values above 100 indicate that the model cannot be used for prediction.

Figure 14 shows the results of modeling intensity spectra using model M1 for all selected values of PD generation voltage.

Figures 15 and 16(a) depict values of fitting parameters: $R^{2}$, RMSE, and SSE obtained by the regression using model M1 for data recorded during each five measurements conducted by different PD generation values.

Model M1 for PD generation voltage values of $65 \mathrm{kV}$ and $70-80 \mathrm{kV}$ obtained an excellent adequacy level, which was confirmed by the obtained values, over 0.6. However, no fitting was obtained for other voltages. The coefficients RMSE and SSE that reached values above 100 indicate that the model cannot be used for prediction. 


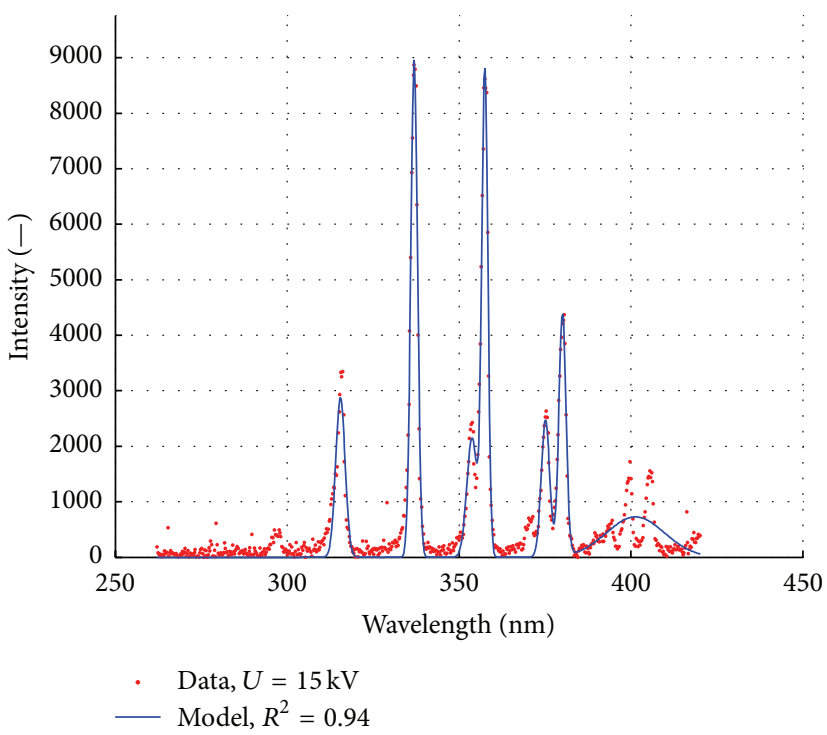

(a)

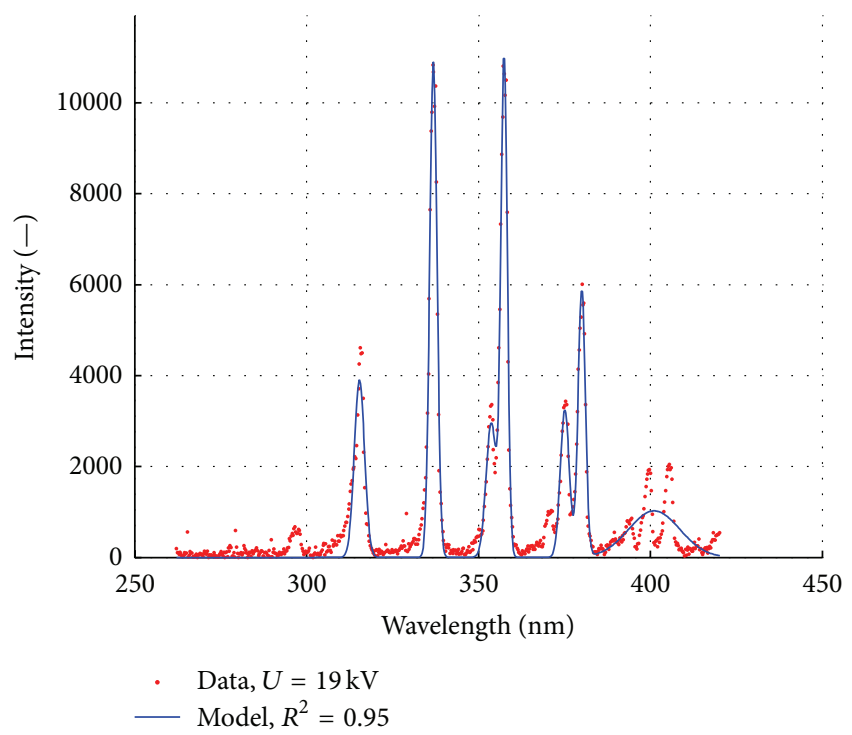

(b)

FIGURE 7: Intensity spectra of recorded and modeled light emission for selected values of PD generation voltages: (a) $0.75 U_{p}=15 \mathrm{kV}$ and $(\mathrm{b})$ $0.94 U_{p}=19 \mathrm{kV}$.

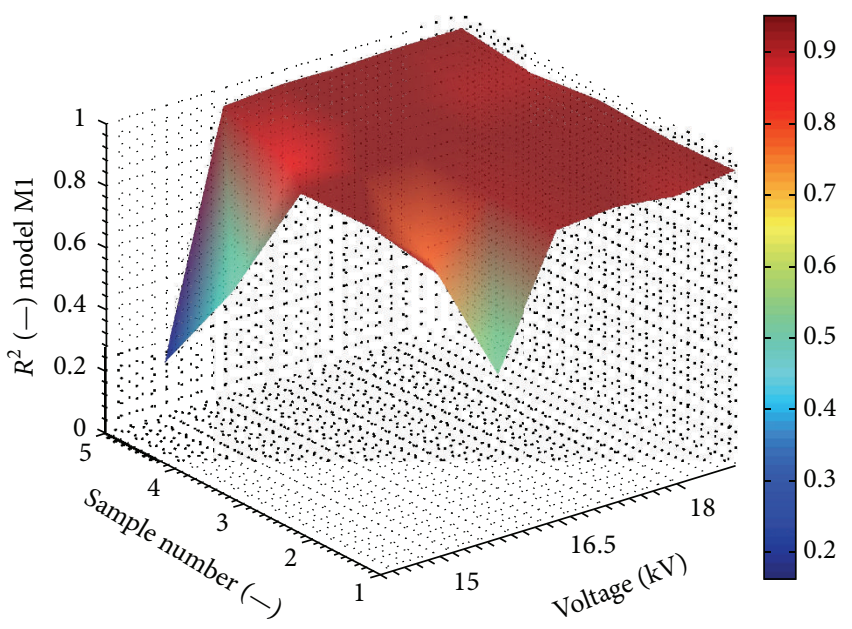

(a)

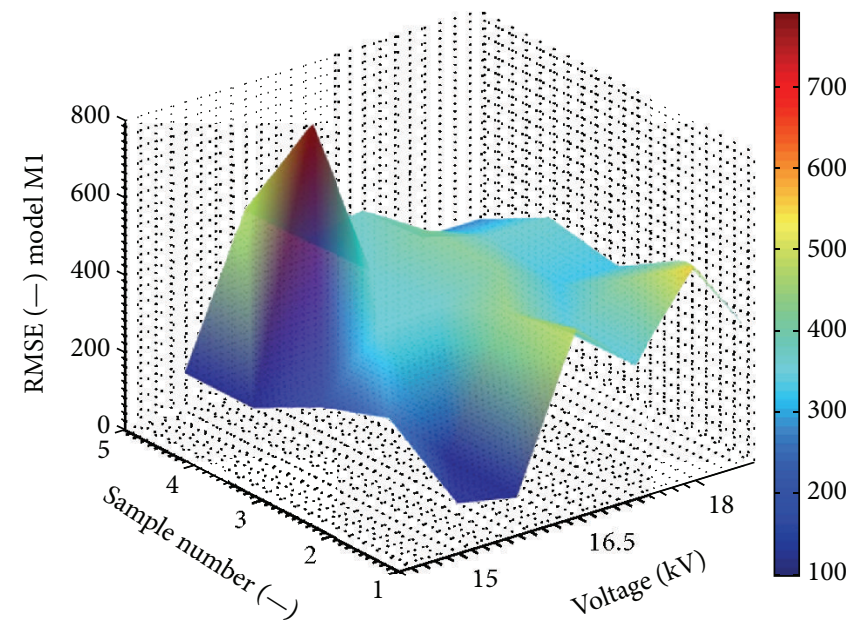

(b)

FIGURE 8: Comparison of values of $R^{2}$ (a) and RMSE (b) coefficients obtained by the regression of the model M1 for all the recorded signals.

Figure 16(b) presents the intensity of individual wavelengths depending on the value of voltage supplying given system.

\subsection{Analysis of Emission Spectra of Discharges Occurring} on the Surface of LS-Type Long Rod Insulator. Figure 17 depicts a cumulative comparison of histograms calculated for spectra of highest intensities obtained during measurements as a function of PD generation value. Figure 17(a) refers to the intensity exceeding the value of $500(I>500)$ and Figure 17(b) to the intensity exceeding the value of 2000 ( $I$ > 2000).

For intensities of values exceeding 2000, dominant light wavelengths occurring in the recorded signals were
TABLE 4: Dominant wavelengths present in light emission of value I $>2000$.

\begin{tabular}{lc}
\hline $\begin{array}{l}\text { Wavelength interval } \\
(\mathrm{nm})\end{array}$ & $\begin{array}{c}\text { Dominant wavelengths and intervals } \\
\text { present in light emission of value } \\
I>2000(\mathrm{~nm})\end{array}$ \\
\hline$\lambda=[200-299]$ & - \\
$\lambda=[300-399]$ & $315-317,335-338,353-358,379-381$ \\
$\lambda=[400-499]$ & - \\
$\lambda>500$ & 724 \\
\hline
\end{tabular}

determined for the individual intervals and presented in Table 4 . 


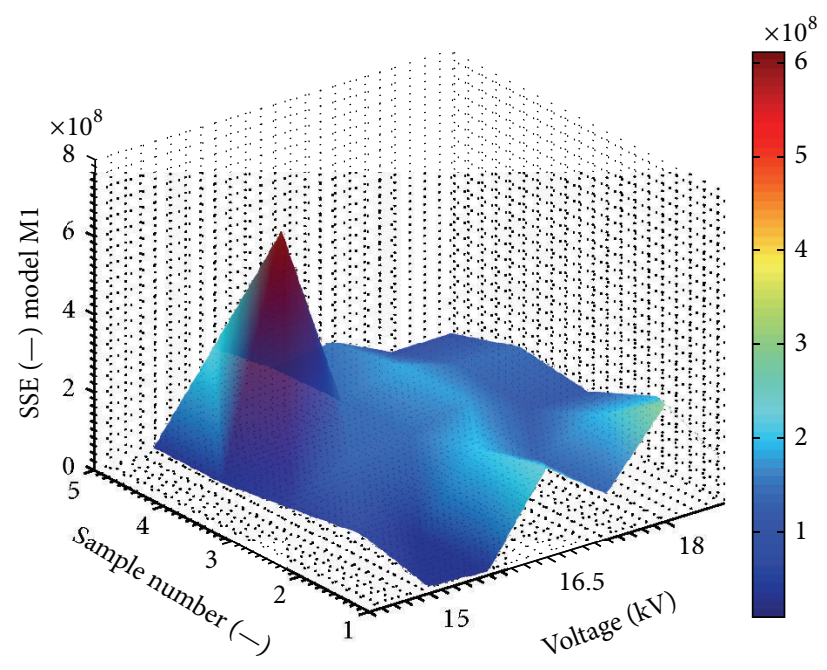

(a)

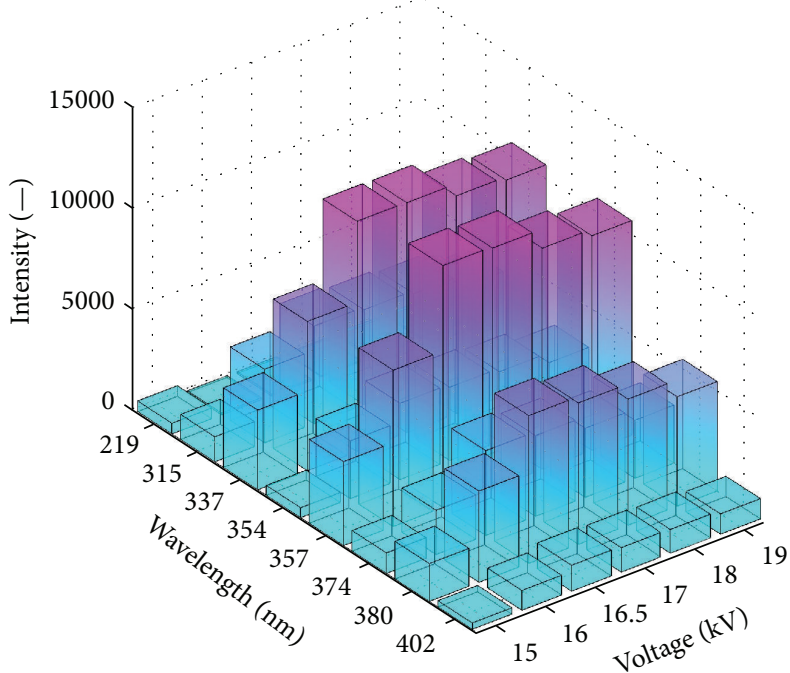

(b)

FIGURE 9: (a) Voltage dependency on SSE obtained by model M1 for all data samples. (b) Intensity of wavelength components obtained by model $\mathrm{Ml}$ as a function of PD generation voltage.

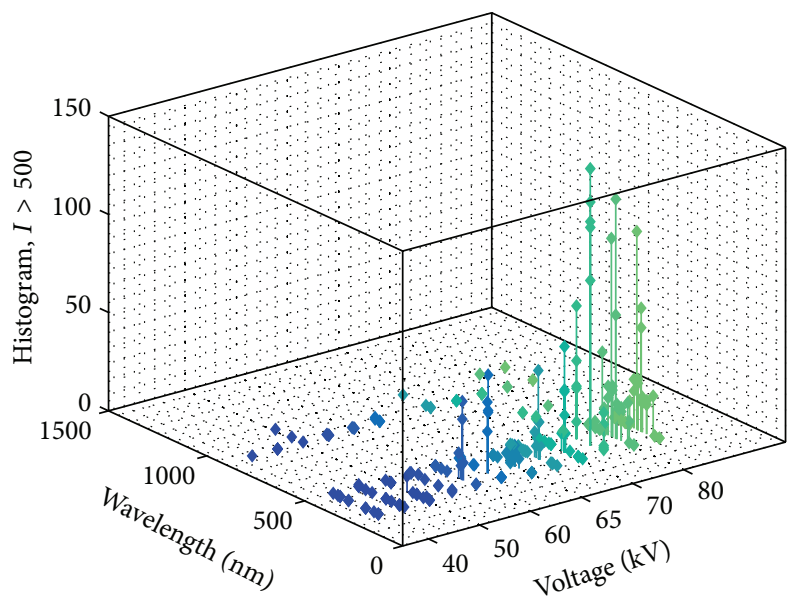

(a)

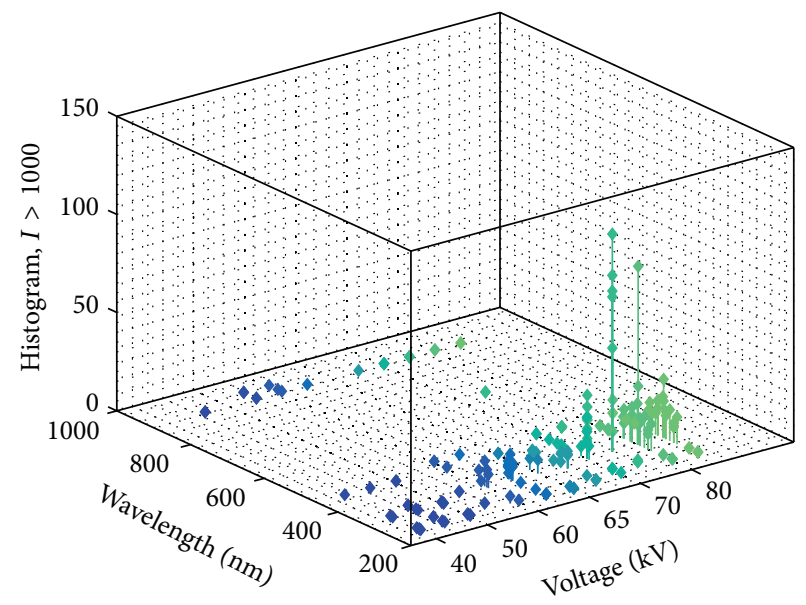

(b)

FIGURE 10: Summary of spectrum intensity histograms for different voltages: (a) $I>500$ and (b) $I>1000$.

Figure 18 presents the results of modeling (blue line) intensity spectra using model M2 for selected values of PD generation voltage and experimental results (red line).

Figures 19 and 20 show values of fitting parameters: $R^{2}$, RMSE, and SSE obtained from the regressions using model M2 for data recorded during each five measurements conducted by various PD generation values. It was found that model M2 obtained an excellent adequacy level in most cases, which was confirmed by the obtained values, $R^{2}$ above 0.6 . Only for the $37.5 \mathrm{kV}$ no fitting was obtained. From Figure 20 it is to conclude that the model cannot be used for prediction.

Figure 21 presents results of modeling (blue color) intensity spectra using model M1 for selected values of PD generation voltage. Red dots denote experimental results.
Figures 22 and 23 depict values of fitting parameters: $R^{2}$, RMSE, and SSE obtained by the regression using model M1 for data recorded during each of five measurements conducted for various $\mathrm{PD}$ generation values.

It was found that model M1 gives very good fitting for signals registered in voltage values over $40 \mathrm{kV}$, which was proven by the $R^{2}$ values over 0.8 . No fitting was obtained at $37.5 \mathrm{kV}$ in 4 of 5 samples. Figure 23(b) depicts the PD generation voltage dependency on the intensity of individual wavelengths.

\section{Conclusions}

Conducting tests with spectrophotometer allowed precise determination of lines length and corresponding intensities 


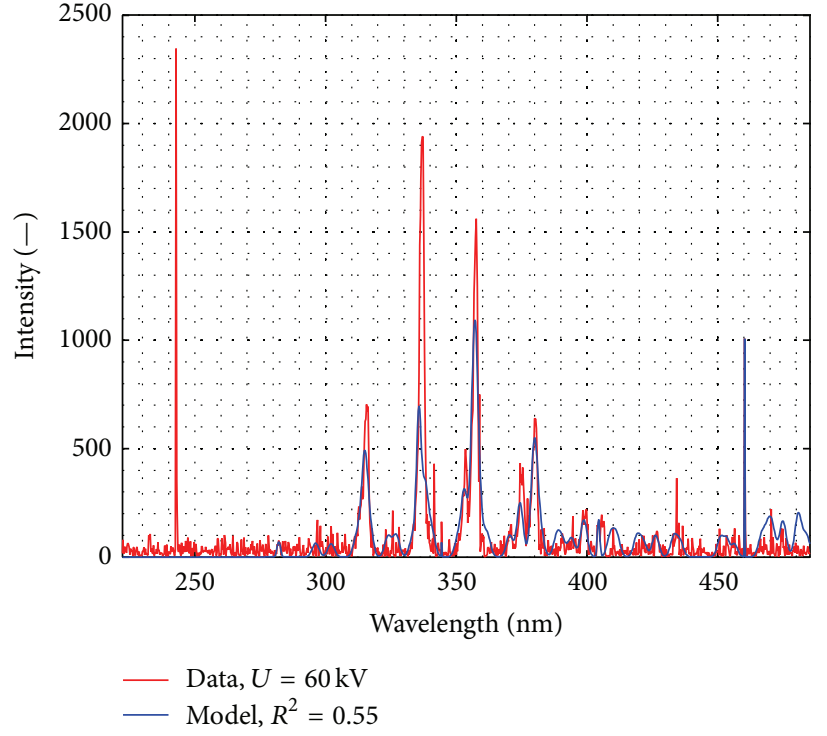

(a)

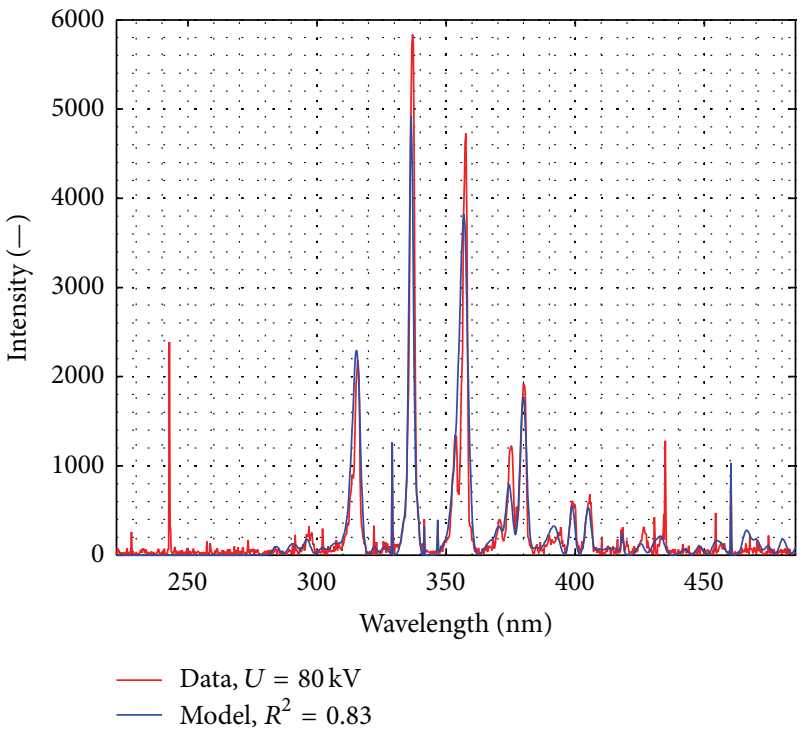

(b)

FIGURE 11: Intensity spectra of recorded and modeled light emission for selected values of PD generation voltages: (a) $0.56 U_{p}=60 \mathrm{kV}$ and (b) $0.89 U_{p}=80 \mathrm{kV}$.

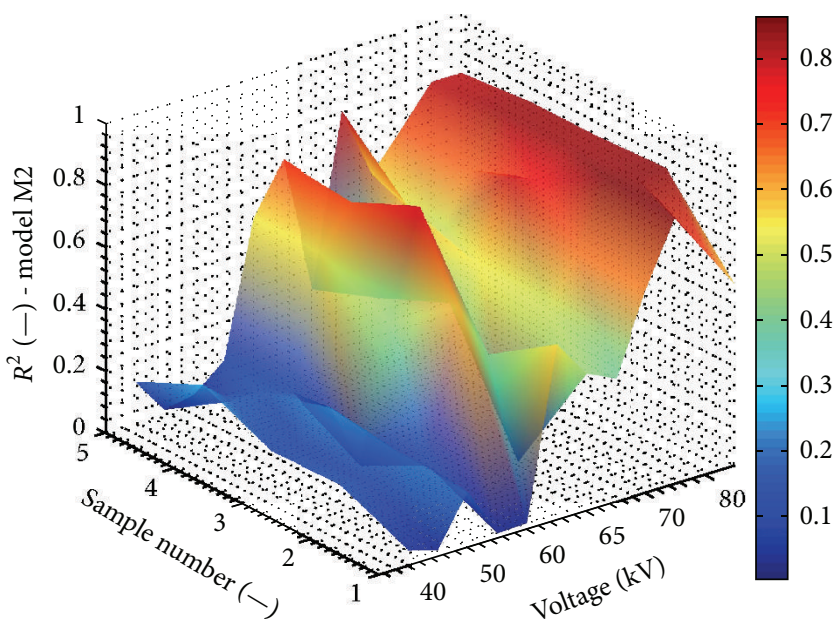

FIGURE 12: Comparison of $R^{2}$ obtained by regression of model M2 for all the recorded signals.

in the recorded optical signals. Based on the obtained dependencies of intensities of emission spectrum emitted by PD generated on studied dielectrics and insulation system the following was concluded:

(i) During PD generation on the surface of a porcelain insulating cylinder filled with quartz, while the distance between electrodes was $3 \mathrm{~cm}$, the highest intensities reaching 10,000 were obtained for spectral lines in a wavelength range of 333-340 and 351$360 \mathrm{~nm}$, when the system was supplied with voltage in a range from $16.5 \mathrm{kV}$ to $19 \mathrm{kV}$.

(ii) During PD generation on the surface of a porcelain insulating cylinder filled with quartz, while the distance between electrodes was $5 \mathrm{~cm}$, the highest intensities reaching 10,000 were obtained for spectral lines in a wavelength range of 331-341 and 349$362 \mathrm{~nm}$, when system was supplied with voltage in a range from $25.5 \mathrm{kV}$ to $27 \mathrm{kV}$.

(iii) During PD generation on the surface of a porcelain insulating cylinder filled with quartz, while the distance between electrodes was $7 \mathrm{~cm}$, the highest intensities reaching 6000 were obtained for spectral lines in a wavelength range of 335-339 and 352$359 \mathrm{~nm}$, when the system was supplied with voltage in a range from $31.5 \mathrm{kV}$ to $33.5 \mathrm{kV}$.

(iv) During PD generation on the surface of a porcelain insulating cylinder filled with quartz, while the distance between electrodes was $9 \mathrm{~cm}$, the highest 


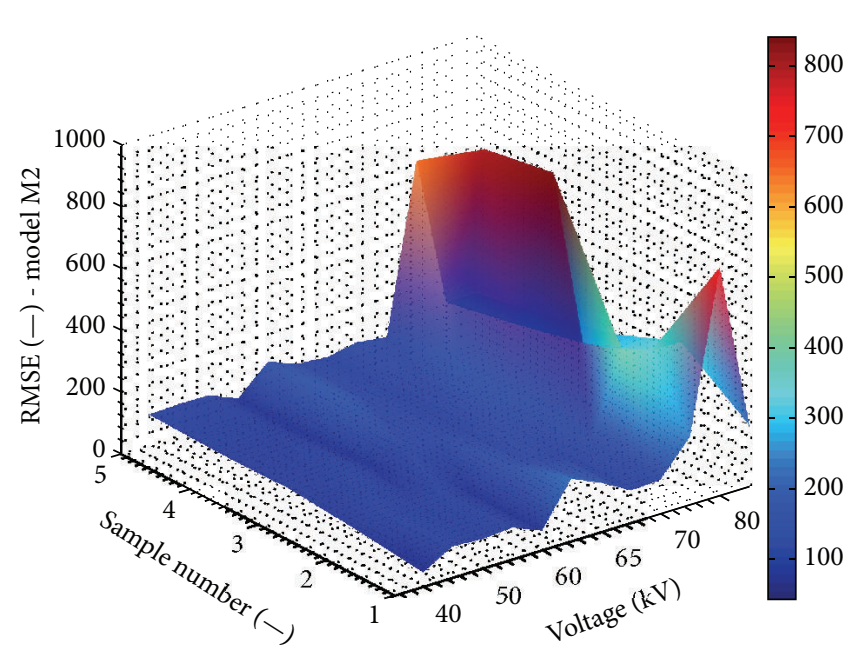

(a)

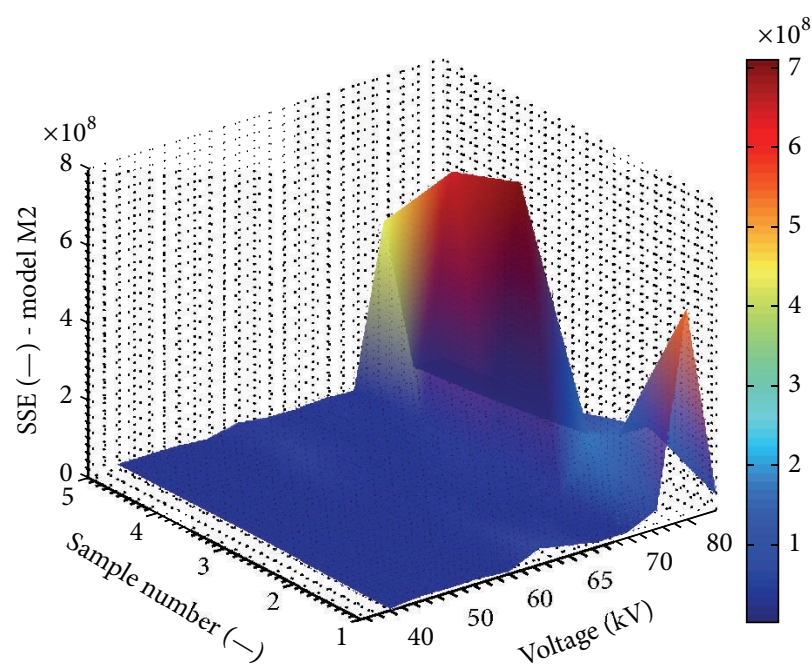

(b)

FIgURE 13: Comparison of RMSE (a) and SSE (b) obtained by regression of model M2 for all data samples.

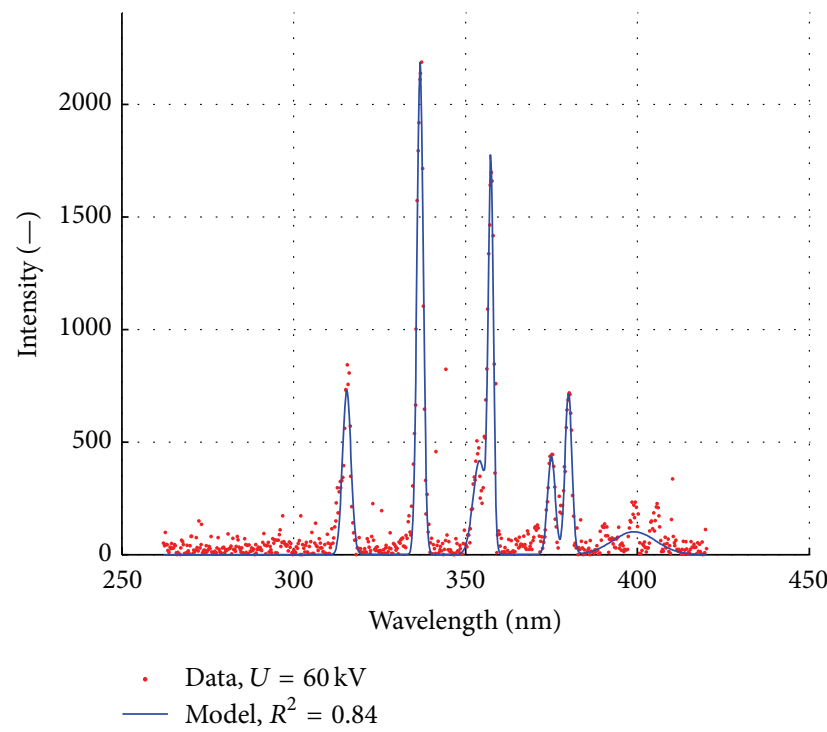

(a)

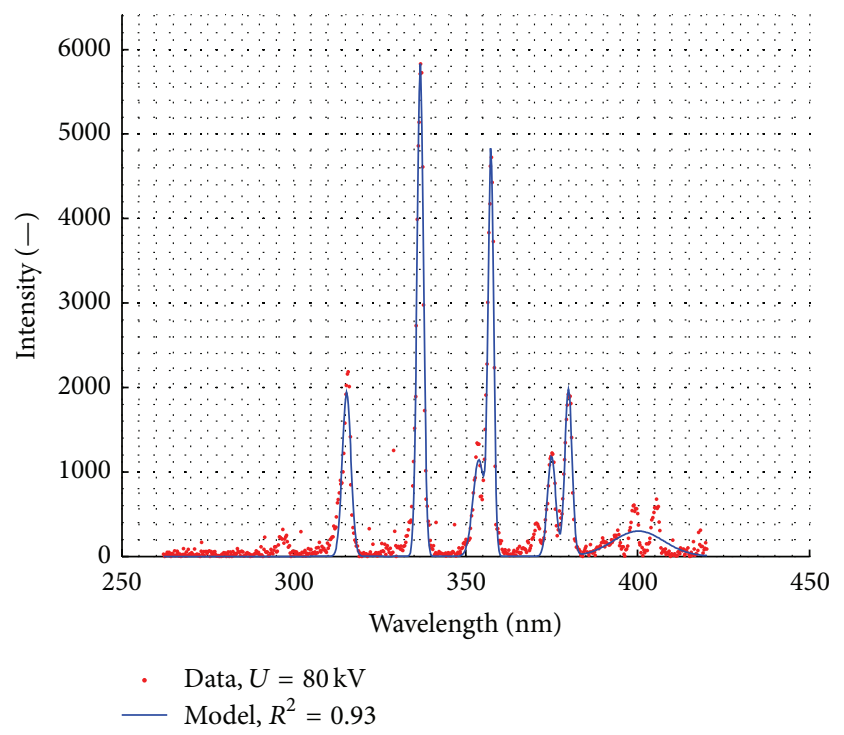

(b)

FIGURE 14: Intensity spectra of recorded and modeled light emission for selected values of PD generation voltages: (a) $0.56 U_{p}=60 \mathrm{kV}$ and (b) $0.89 U_{p}=80 \mathrm{kV}$.

intensities reaching 2000 were obtained for spectral lines in a wavelength range of 336-338, 354, and 356$359 \mathrm{~nm}$, when the system was supplied with voltage in a range from $39 \mathrm{kV}$ to $41 \mathrm{kV}$ and $43 \mathrm{kV}$ to $46 \mathrm{kV}$.

(v) During PD generation on the surface of a porcelain insulating cylinder filled with quartz, while the distance between electrodes was $9 \mathrm{~cm}$, the highest intensities reaching 2000 were obtained for spectral lines in a wavelength range of 335-339 and 353$359 \mathrm{~nm}$, when the system was supplied with voltage in a range from $44 \mathrm{kV}$ to $45 \mathrm{kV}$ and for approximately $50 \mathrm{kV}$. (vi) By analyzing the influence of distance on the obtained results, one can conclude that the range of components decreases with increasing distance, which is probably a result of the suppression of individual spectral lines in the air.

(vii) During PD generation on a cap insulator made of porcelain, the highest intensities, over 9000, were obtained for spectral lines in ranges 333-339 and 352371. The insulator was supplied with voltage of values in a range from $72 \mathrm{kV}$ to $76 \mathrm{kV}$.

(viii) During PD generation on an individual cap of porcelain long rod insulator, the highest intensities, over 


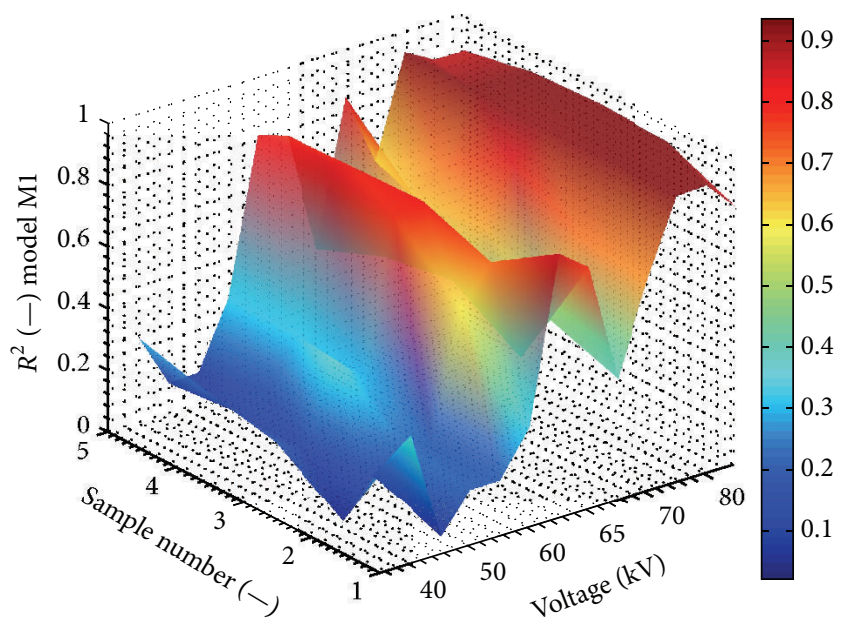

(a)

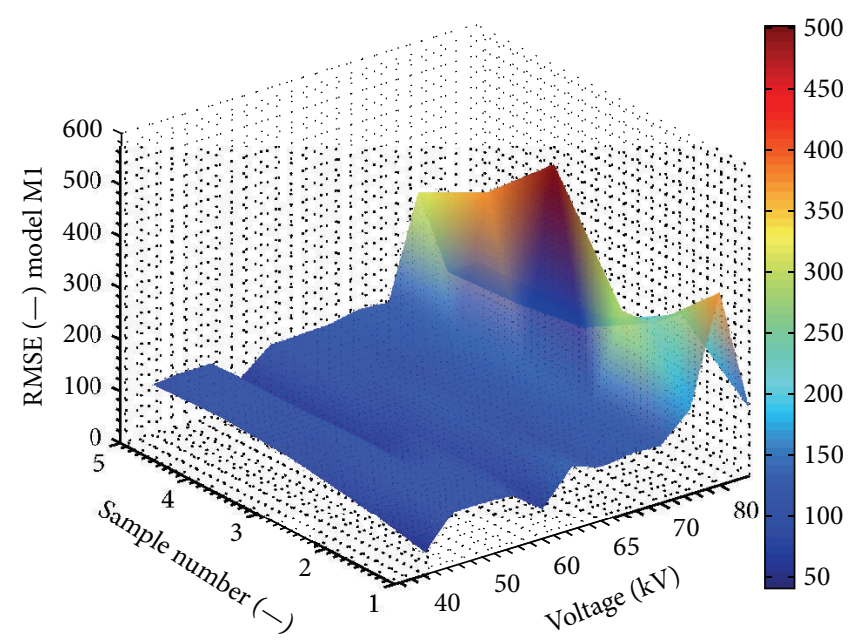

(b)

FIGURE 15: Comparison of $R^{2}$ (a) and RMSE (b) obtained by regression of model M1 for all data samples.

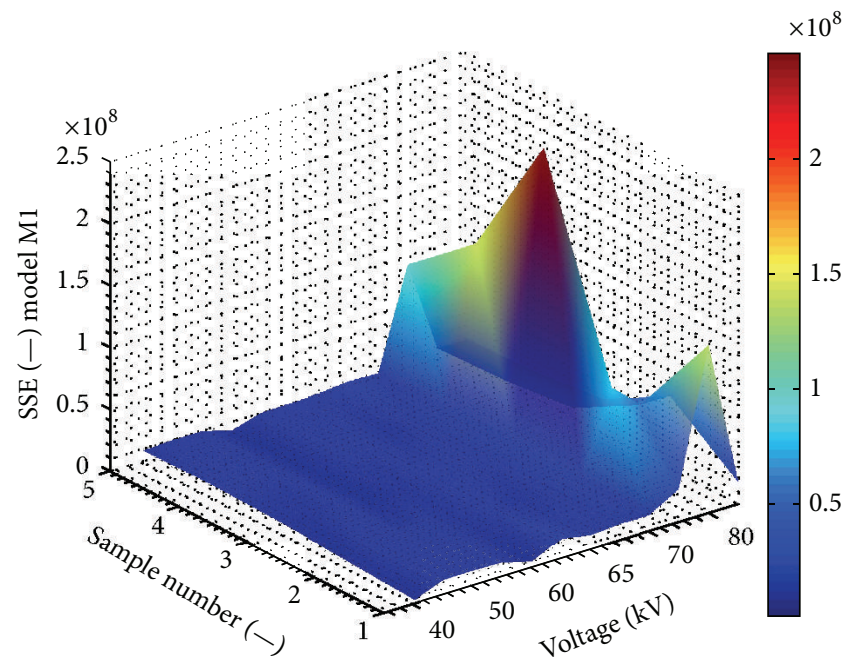

(a)

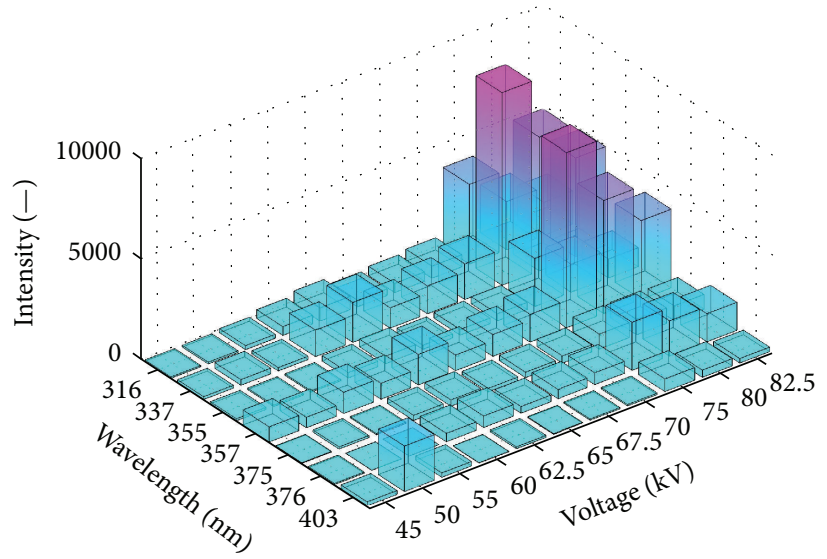

(b)

FIGURE 16: (a) Comparison of SSE coefficient obtained by regression of model M1 for all recorded signals. (b) Voltage dependence of intensity of individual wavelengths obtained by model M1.

6000 , were obtained for spectral lines in ranges 335338 and 353-358. The insulator was supplied with voltage of values in a range from $42.5 \mathrm{kV}$ to $46 \mathrm{kV}$.

Table 5 shows a comparison between PD initial voltage values $U_{0}$ and $U_{01}$, during which the measurement device recorded first light emission waves $\left(U_{01}\right)$ or when the recorded spectra included the most components of increased (over 300) intensities $\left(U_{0}\right)$, depending on the test system. The analysis of the values presented in Table 5 allows one to conclude that the application of the spectrophotometer enables earlier recognition of $\mathrm{PD}$ generation, which confirms the thesis of the study. On average, the increased performance was estimated as a lower level of voltage, $42 \%$.
Based on the obtained results, Table 6 presents a comparison of dominant wavelengths contained in light emission of intensities exceeding 1000, obtained for individual dielectrics and ceramic insulators.

The comparison of the data presented in Table 6 allows one to formulate the following general conclusions:

(i) PD emitted electromagnetic waves in a range of 300$400 \mathrm{~nm}$ regardless of in which dielectric and insulator system they are generated.

(ii) PD emitted waves of $203 \mathrm{~nm}$ length on a porcelain cylinder filled with quartz, except when the HV electrode was placed at a distance between electrodes of $11 \mathrm{~cm}$. 


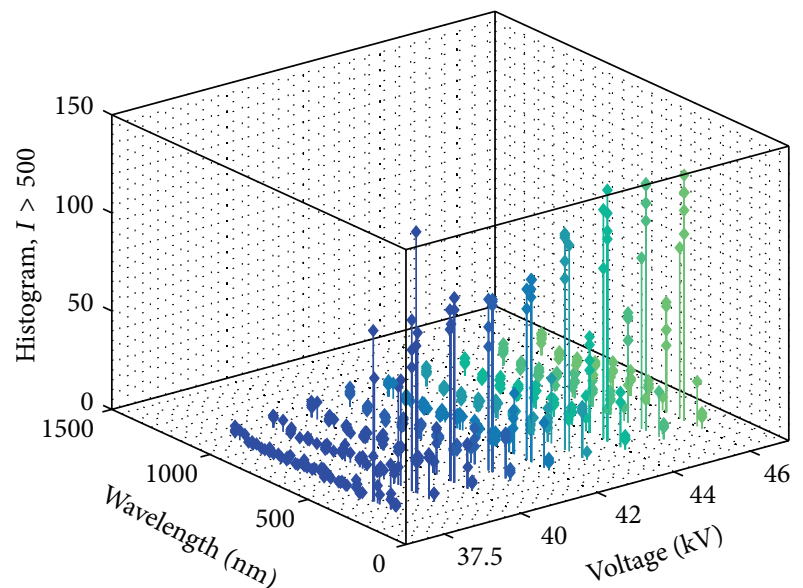

(a)

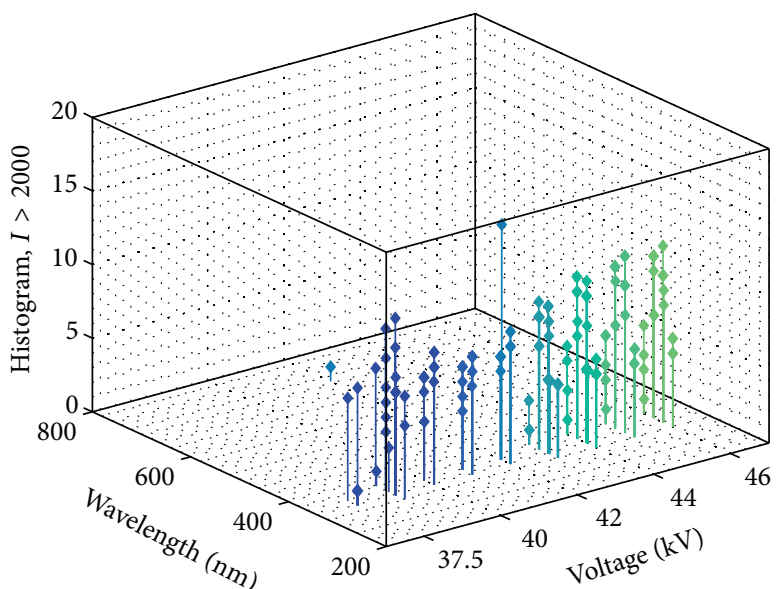

(b)

FIGURE 17: Summary of spectrum intensity histograms for different voltages: (a) $I>500$ and (b) $I>2000$.

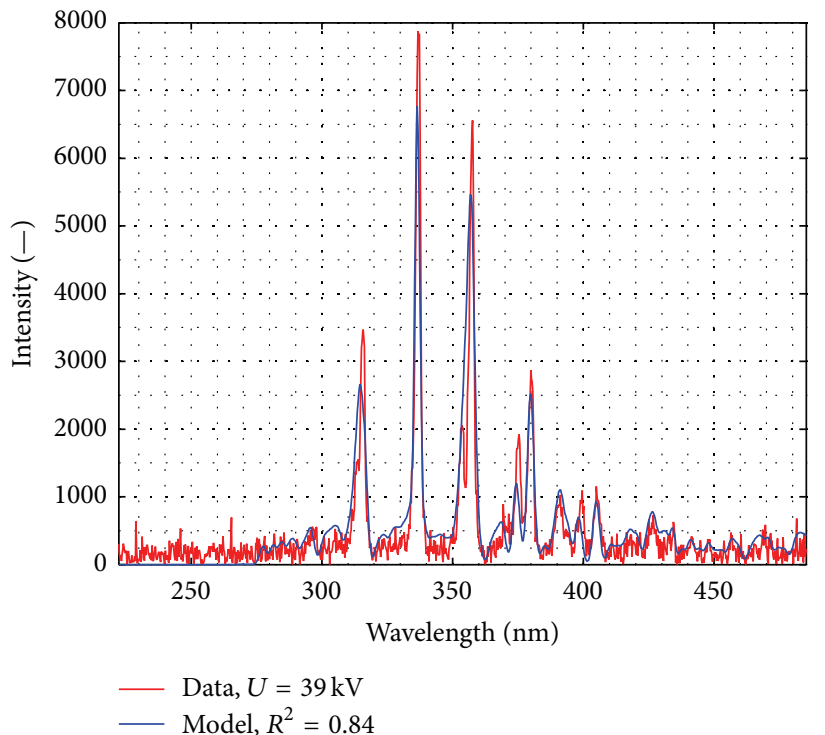

(a)

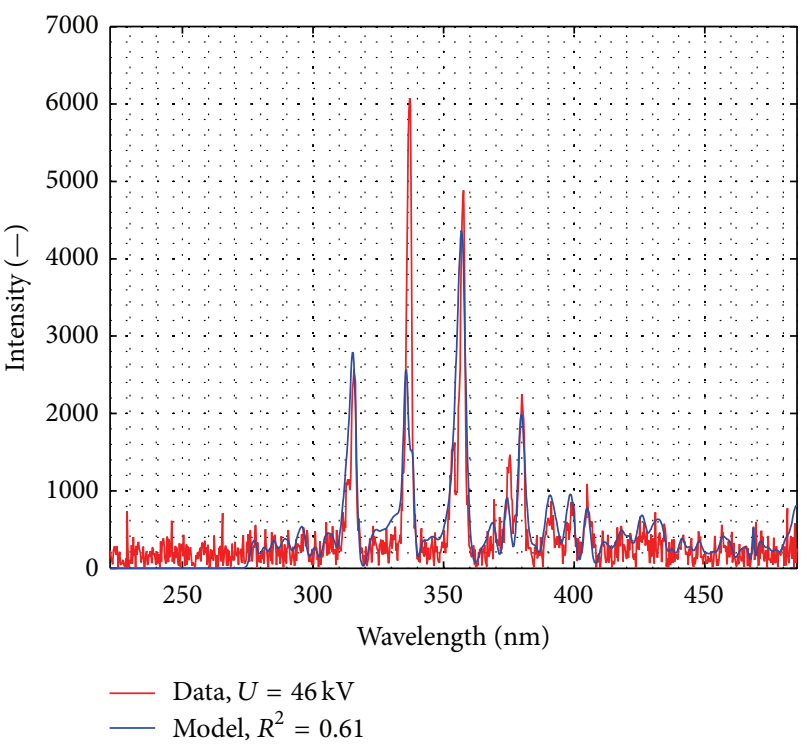

(b)

FIGURE 18: Intensity spectra of recorded and modeled light emission for selected values of PD generation voltages: $(\mathrm{a}) 0.81 U_{p}=39 \mathrm{kV}$ and (b) $0.95 U_{p}=46 \mathrm{kV}$.

TABLE 5: Comparison of PD initial voltages for tested insulation systems, during which emission spectra may have increased intensity and the broadest range.

\begin{tabular}{|c|c|c|c|c|c|c|c|}
\hline & \multicolumn{7}{|c|}{$\begin{array}{c}\text { Values of initial voltages } U_{0} \text { and } U_{01} \text { for tested } \\
\text { insulation systems }\end{array}$} \\
\hline & WPK & WPK & WPK & WPK & WPK & LK & LS \\
\hline & $3 \mathrm{~cm}$ & $5 \mathrm{~cm}$ & $7 \mathrm{~cm}$ & $9 \mathrm{~cm}$ & $11 \mathrm{~cm}$ & - & - \\
\hline$U_{0}$ & $9.9 \%$ & $18.2 \%$ & $23.6 \%$ & $24.3 \%$ & $25.7 \%$ & $23.3 \%$ & $12 \%$ \\
\hline$U_{01}$ & $15.5 \%$ & $25.5 \%$ & $30.5 \%$ & $37 \%$ & $39 \%$ & $72 \%$ & $37.5 \%$ \\
\hline Difference & $36.2 \%$ & $28.6 \%$ & $22.6 \%$ & $34.3 \%$ & $34.1 \%$ & $67.6 \%$ & $68 \%$ \\
\hline
\end{tabular}




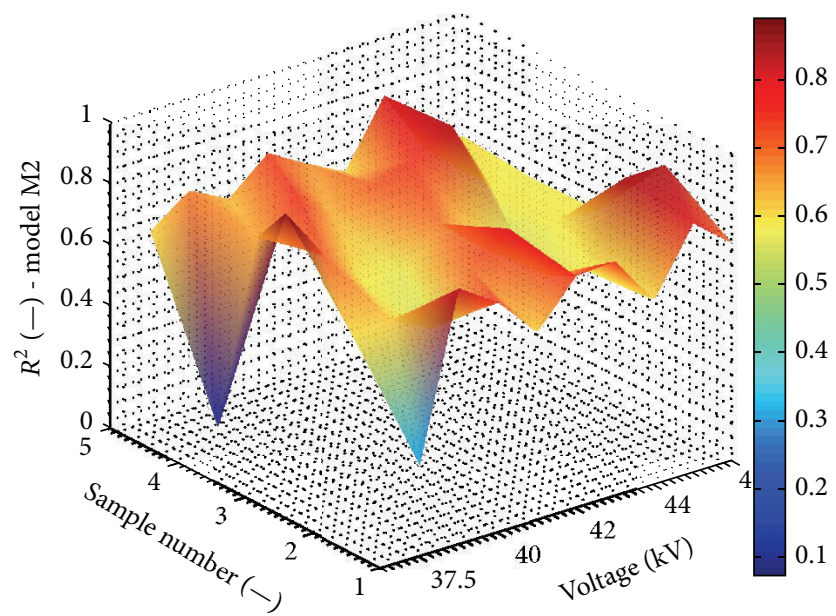

FIGURE 19: Comparison of $R^{2}$ coefficient obtained by regression of model M2 for all the recorded signals.

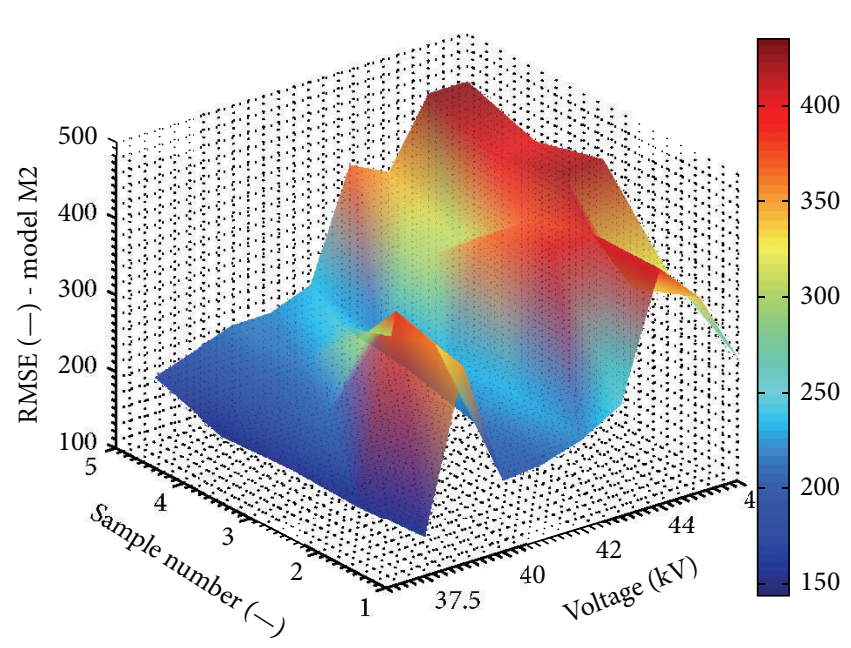

(a)

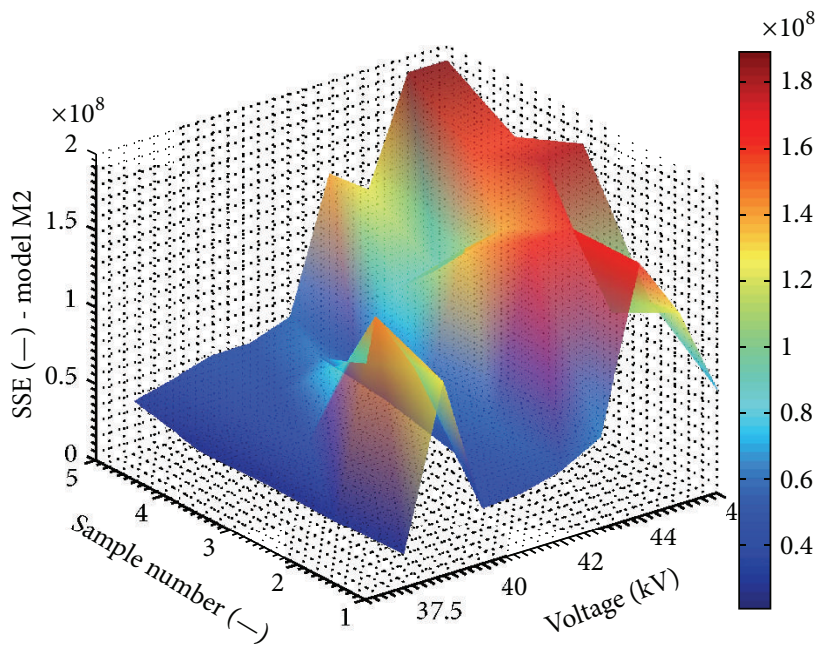

(b)

FIGURE 20: Comparison of RMSE (a) and SSE (b) obtained in model M2 for all the recorded signals.

TABLE 6: Comparison of the dominating wavelengths present in light emission of value $I>1000$ for all tested dielectrics and ceramic insulators.

\begin{tabular}{|c|c|c|c|c|}
\hline \multirow{2}{*}{$\begin{array}{l}\text { System symbol } \\
\text { WPK } 3\end{array}$} & \multicolumn{4}{|c|}{ Values and ranges of recorded optical waves $\lambda(\mathrm{nm})$ exhibiting intensity $I>1000$} \\
\hline & 203, 296-298 & $\begin{array}{c}311-318,333-340,351-360 \\
369-382,390-396,397-399\end{array}$ & $\begin{array}{c}400-401,404-407,420,425-428 \\
434-435\end{array}$ & $745,933,1073$ \\
\hline WPK 5 & $203,295-299$ & $\begin{array}{c}309-318,328-329,331-341 \\
349-362,366-383,386 \\
388-399\end{array}$ & $\begin{array}{c}400-407,414,416,418-421 \\
424-428,431-435,449,456-458\end{array}$ & $\begin{array}{c}607,653-654,658-663,667-671 \\
676-678,724,745,774,793,913 \\
933,1062,1073\end{array}$ \\
\hline WPK 7 & 203 & $\begin{array}{l}306-317,335-339,352-359 \\
374-382,386,393-394,399\end{array}$ & $400,405-406,423$ & $\begin{array}{c}587-594,640,720,745,766-768 \\
770-771,793,933\end{array}$ \\
\hline WPK 9 & 203 & $\begin{array}{c}315-317,336-338,354 \\
356-359,375-376,379-381\end{array}$ & - & $660,724,813,933$ \\
\hline WPK 11 & - & $\begin{array}{c}313-317,335-339,353-359 \\
374-377,379-382,399\end{array}$ & 400,406 & $660,724,739$ \\
\hline LS & - & $\begin{array}{c}315-317,335-338,353-358 \\
379-381\end{array}$ & - & 724 \\
\hline LK & 243 & $\begin{array}{c}312-317,329,333-339 \\
352-371,373-382,398-399\end{array}$ & $400,404-406,435,460$ & 724,933 \\
\hline
\end{tabular}




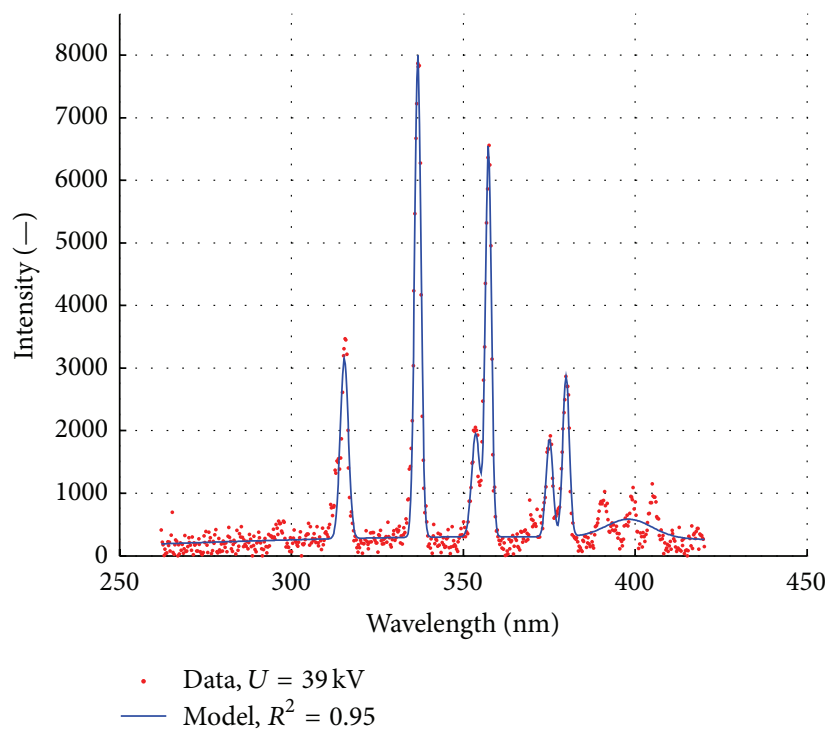

(a)

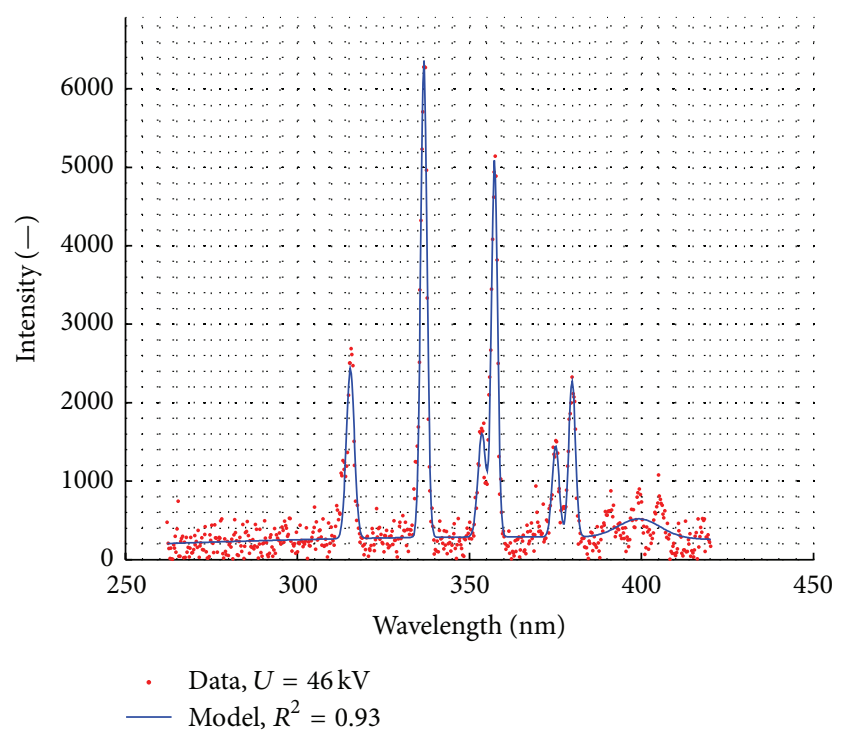

(b)

FIGURE 21: Intensity spectra of recorded and modeled light emission for selected values of PD generation voltages: (a) $0.81 U_{p}=39 \mathrm{kV}$ and (b) $0.95 U_{p}=46 \mathrm{kV}$.

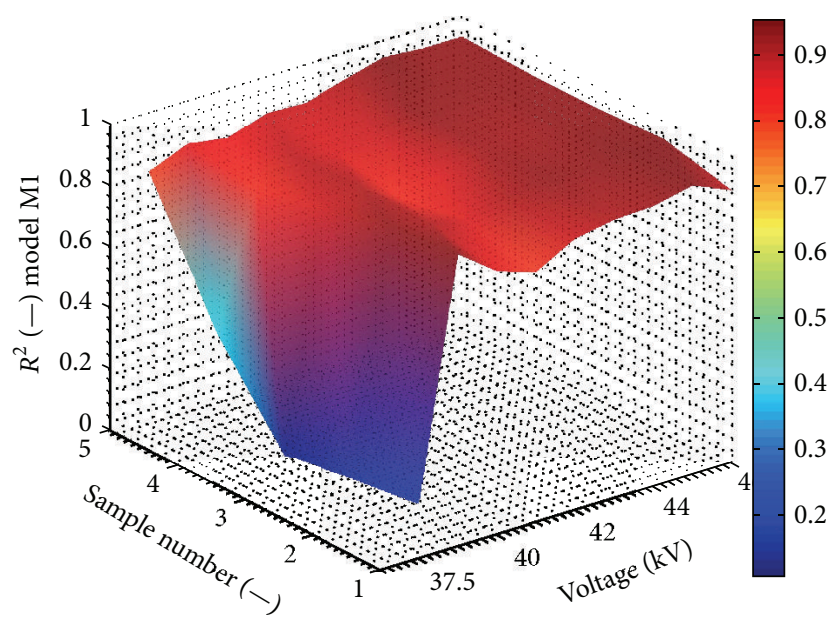

(a)

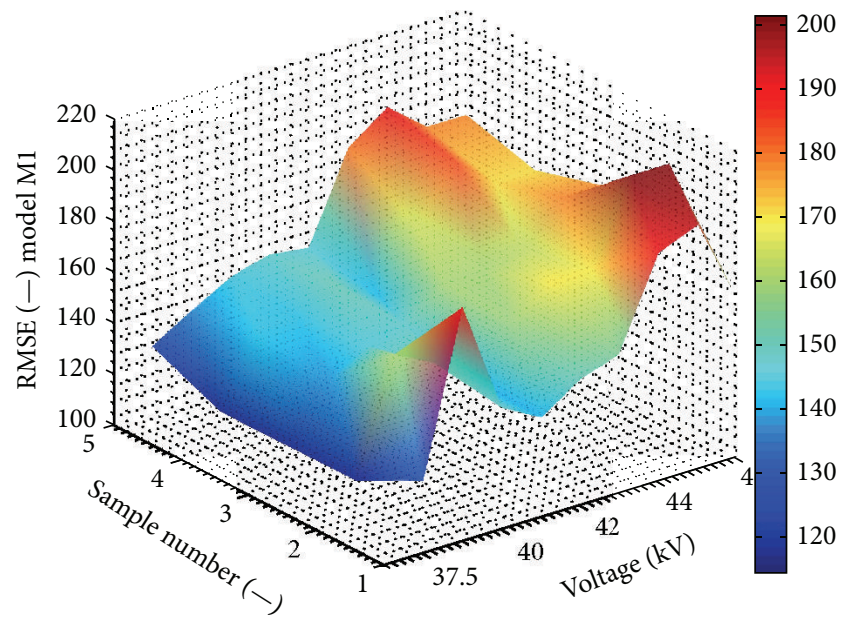

(b)

FIGURE 22: Comparison of $R^{2}$ (a) and RMSE (b) coefficient obtained in model M1 for all the recorded signals.

(iii) PD occurring on the surface of the tested cap insulator are characterized by the presence of waves of $243 \mathrm{~nm}$ length.

(iv) PD occurring on the porcelain cylinder with a $\mathrm{HV}$ electrode placed at distances between electrodes of $3 \mathrm{~cm}$ and $5 \mathrm{~cm}$ emitted waves of 295-299 $\mathrm{nm}$ length.

(v) PD emitted many waves in a range of 400-500 when they occurred on a porcelain cylinder with a $\mathrm{HV}$ electrode placed at distances between electrodes of $3 \mathrm{~cm}$ and $5 \mathrm{~cm}$. Single waves in this range were emitted on cap insulators and other types of insulating cylinders, except for cylinder tested at a distance between electrodes of $9 \mathrm{~cm}$. PD occurring on the porcelain long rod insulator did not emit any optical waves in this range.

(vi) EM waves in visible light range, above $500 \mathrm{~nm}$, were present in spectra in different ways. Most components from this range were recorded on porcelain roll insulators during PD generation at distances of $5 \mathrm{~cm}$ and $7 \mathrm{~cm}$.

(vii) The lowest number of spectral components was generated by PD occurring on the long rod insulator made of porcelain.

Figures 24-26 present a comparison showing the averaged values of fitting coefficients of regression models $\mathrm{M} 1$ and M2 to empirical data: SSE (4), $R^{2}(6)$, and RMSE (5). 


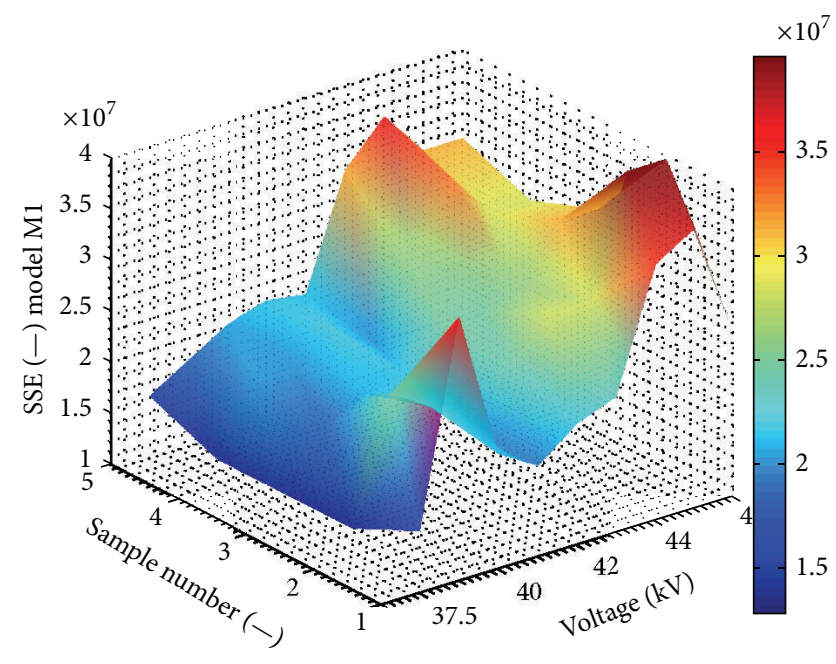

(a)

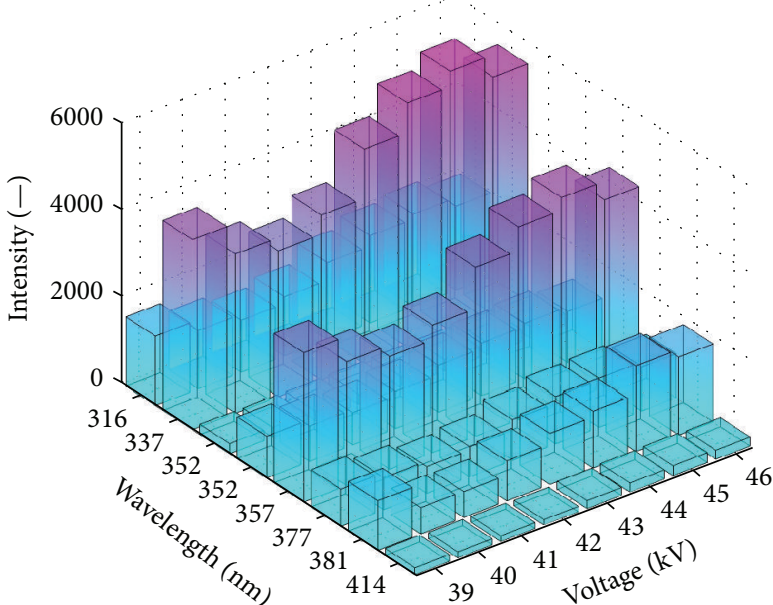

(b)

FIGURE 23: (a) Comparison of SSE coefficient values obtained in model M1 for all the recorded signals. (b) Dependence of the intensity of individual wavelengths as a function of PD generation voltage.
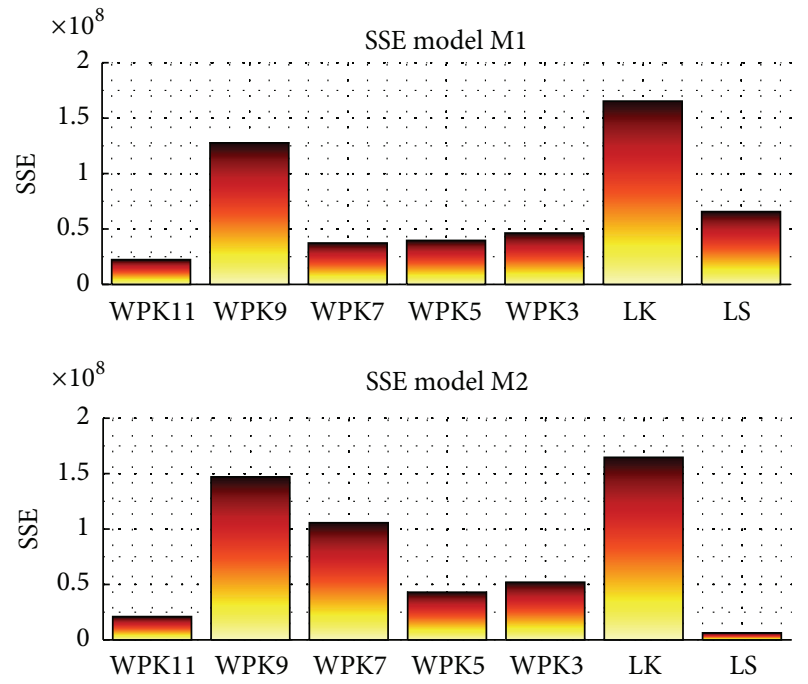

FIGURE 24: Comparison of the averaged values of the SSE coefficient obtained by the regression of models M1 and M2 for all the tested dielectrics and insulation systems.

The comparative analysis of models M1 and M2 fitting coefficients, which describe the dependency of intensity of emission spectra as a function of wavelength, may serve as a justification for the following statements:

(i) The values of coefficients SSE and RMSE are similar in both models. The tested insulation system exhibited high values of these parameters, which proves that these models are not optimal for prediction applications.

(ii) Regarding the comparison of determination coefficient values, $R^{2}$, obtained for the M1 model, we may conclude that good fitting was observed only
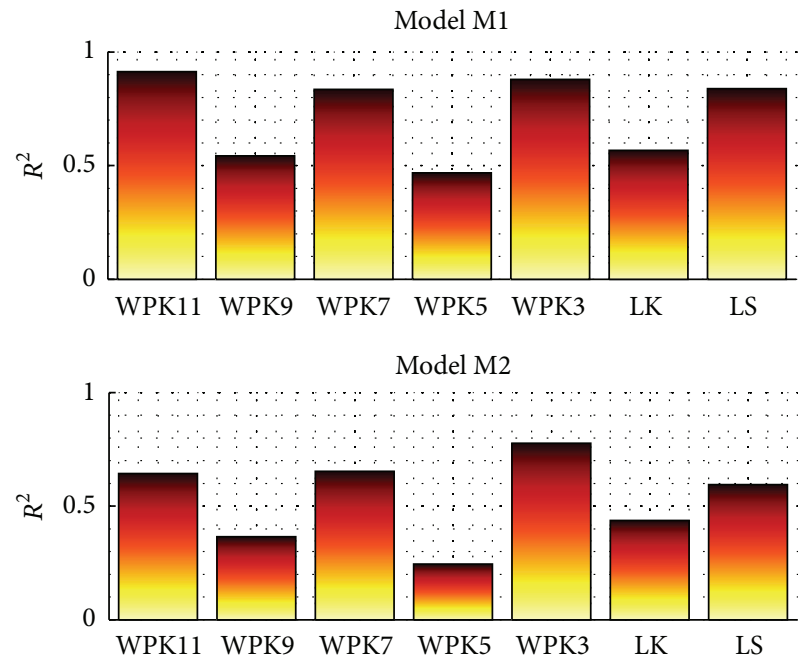

FIGURE 25: Comparison of the averaged values of the $R^{2}$ coefficient obtained by the regression of models M1 and M2 for all the tested dielectrics and insulation systems.

in selected insulation models, including porcelain cylinder at distances of 3,7 , and $11 \mathrm{~cm}$ and in LS-type insulator. The rest of values indicate rather moderate and poor fitting. In case of model M2, all the fitting coefficient values had results of $R^{2}$ below 0.7 , except for the WPK3 system, which also indicates poor fitting of the model to empirical data.

(iii) It should be noted that all of the conclusions mentioned above apply to values that have been averaged "twice"; that is, firstly, the results from five measurements were averaged and then a second averaging was conducted for all PD generation voltages. Therefore, it seems more reasonable to take into consideration 

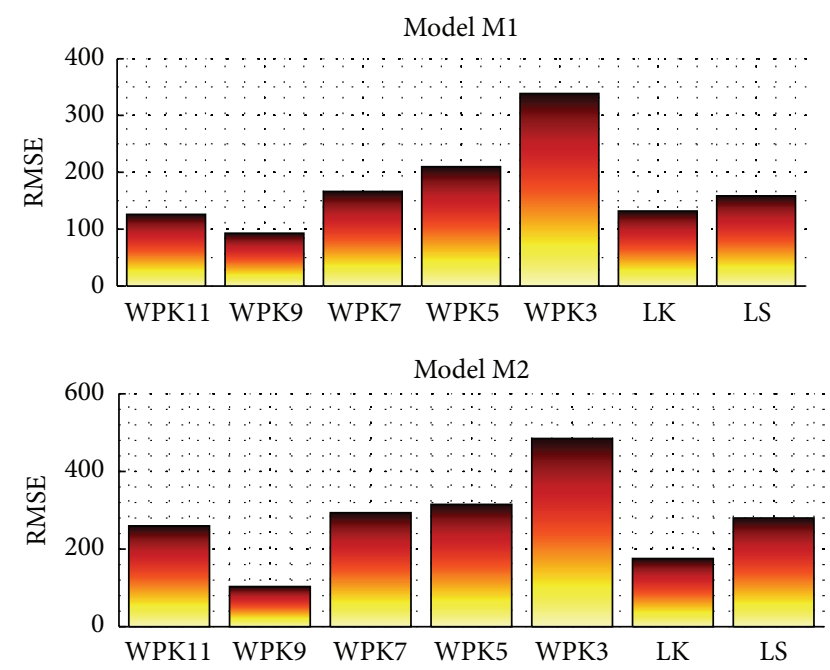

FIgURE 26: Comparison of the averaged values of the RMSE coefficient obtained by the regression of models M1 and M2 for all the tested dielectrics and insulation systems.

the results obtained for values averaged just "once" for individual voltages, which are depicted in Figures 5, 6, 8, 9(a), 12, 13, 15, 16(a), 19, 20, 22, and 23(a).

\section{Competing Interests}

The authors declare that there is no conflict of interests regarding the publication of this paper.

\section{Acknowledgments}

The work was cofinanced with funds from the National Science Centre (NCS) as part of the OPUS program, Project no. 2013/09/B/ST8/01736. The work was cofinanced by the European Regional Development Fund "Increase of Scientific Research and Innovation for Enterprises in Terms of Sustainable Development through the Creation of a Modern Diagnostics Laboratory of Surge Voltage at the Opole University of Technology" Part I (2010-2011) and Part II (20112013), Project nos. RPO.01.03.0101-16-007/10-00 and WNDRPOP.01.03.01-16-007/10.

\section{References}

[1] R. J. van Brunt, "Physics and chemistry of partial discharge and corona-recent advances and future challenges," in Proceedings of the IEEE Conference on Electrical Insulation and Dielectric Phenomena, pp. 29-70, October 1994.

[2] I. J. Kemp, "Partial discharge plant-monitoring technology: present and future developments," IEE Proceedings-Science, Measurement and Technology, vol. 142, no. 1, pp. 4-10, 1995.

[3] A. Aman, M. M. Yaacob, M. A. Alsaedi, and K. A. Ibrahim, "Polymeric composite based on waste material for high voltage outdoor application," International Journal of Electrical Power and Energy Systems, vol. 45, no. 1, pp. 346-352, 2013.

[4] R. Lopatkiewicz, Z. Nadolny, and P. Przybylek, "The influence of water content on thermal conductivity of paper used as transformer windings insulation," in Proceedings of the IEEE 10th International Conference on the Properties and Applications of Dielectric Materials (ICPADM '12), pp. 1-4, IEEE, Bangalore, India, July 2012.

[5] F. Witos and Z. Gacek, "Application of the joint electro-acoustic method for partial discharge investigations within a power transformer," The European Physical Journal Special Topics, vol. 154, no. 1, pp. 239-247, 2008.

[6] A. Cichoń, S. Borucki, and D. Wotzka, "Modeling of acoustic emission signals generated in on load tap changer," Acta Physica Polonica A, vol. 125, no. 6, pp. 1396-1399, 2014.

[7] E. Veldhuizen and W. Rutgers, "Corona discharges: fundamentals and diagnostics," in Proceedings of the 4th Conference on Frontiers in Low Temperature Plasma Diagnostic, pp. 40-49, 2001.

[8] I. A. D. Giriantari, "Monitoring the insulator condition by online voltage distribution measurement," in Proceedings of the International Conference on Condition Monitoring and Diagnosis (CMD '08), pp. 392-394, Beijing, China, April 2008.

[9] A. Blachowicz, T. Boczar, and D. Wotzka, "Application of a mobile system in diagnostics of power capacitors using the acoustic emission method," Insight, vol. 58, no. 2, pp. 94-100, 2016.

[10] A. Cichoń, P. Frącz, and D. Zmarzły, "Characteristic of acoustic signals generated by operation of on load tap changers," Acta Physica Polonica A, vol. 120, no. 4, pp. 585-588, 2011.

[11] R. Badent, K. Kist, A. Schwab, and M. Wurster, "Light emission measurements of predischarges in insulation oil," in Proceedings of IEEE Annual Report Conference on EI and Dielectric Phenomena, vol. 2, pp. 452-455, Atlanta, Ga, USA, 2008.

[12] H. Kojima, N. Hayakawa, F. Endo, and H. Okubo, "Novel measurement and analysis system for investigation of partial discharge mechanism in SF6 gas," in Proceedings of the 12th International Middle East Power System Conference (MEPCON '08), pp. 75-79, Aswan, Egypt, March 2008.

[13] D. Zmarzly, Ł. Nagi, S. Borucki, and T. Boczar, "Analysis of ionizing radiation generated by partial discharges," Acta Physica Polonica A, vol. 125, no. 6, pp. 1377-1379, 2014.

[14] M. Brockschmidt, F. Pohlmann, S. Kempen, and P. Gröppel, "Testing of nano-insulation materials: some ideas, some experiences," in Proceedings of the 30th Electrical Insulation Conference (EIC '11), pp. 506-510, Annapolis, Md, USA, June 2011.

[15] P. Morshuis and E. Gulski, "Diagnostic tools for condition monitoring of insulating materials," in Proceedings of the Conference on Electrical Insulation and Dielectric Phenomena, pp. 327-330, Virginia Beach, Va, USA, October 1995.

[16] W. Tan, W. Huang, K. Wang, and Z. Zhang, "The study of ultraviolet pulse for partial discharge of transformers," in Proceedings of the IEEE World Automation Congress (WAC '08), pp. 1-4, Waikoloa, Hawaii, USA, October 2008.

[17] H. Zhang, Q. Pang, and X. Chen, "The characteristics of highvoltage corona and its detection," Electrical Measurement and Instrumentation, vol. 43, pp. 6-8, 2006.

[18] P. Frącz, T. Boczar, D. Zmarły, and T. Szczyrba, "Analysis of optical radiation generated by electrical discharges on support insulator," Acta Physica Polonica A, vol. 124, pp. 413-416, 2013.

[19] P. Frącz, "Measurement of optical signals emitted by surface discharges on bushing and post insulator," IEEE Transactions on Dielectrics and Electrical Insulation, vol. 20, no. 5, pp. 1909-1914, 2013. 

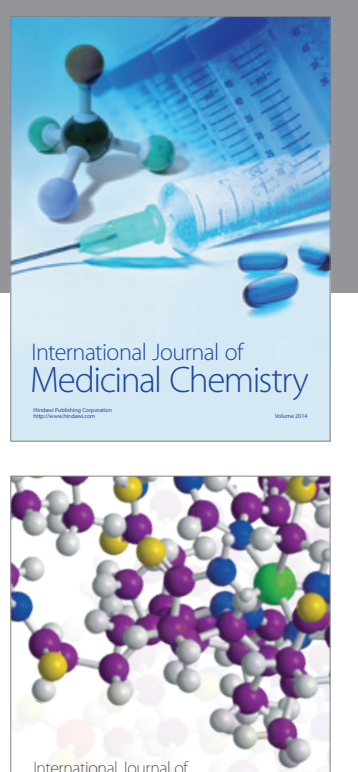

Carbohydrate Chemistry

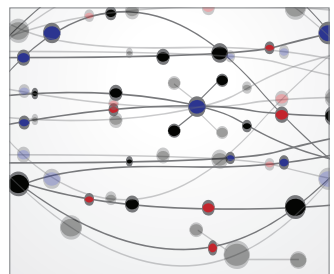

The Scientific World Journal
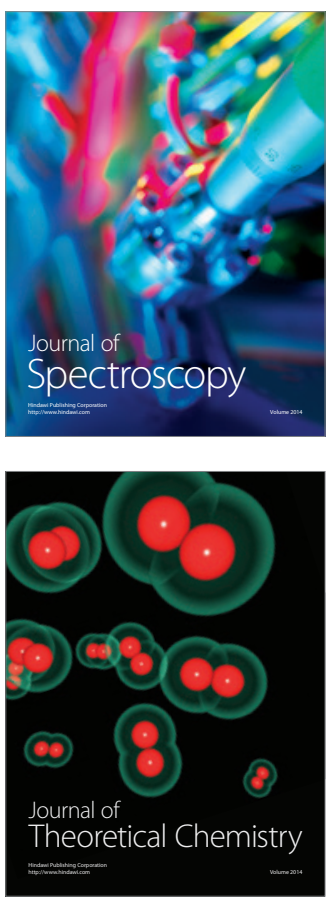
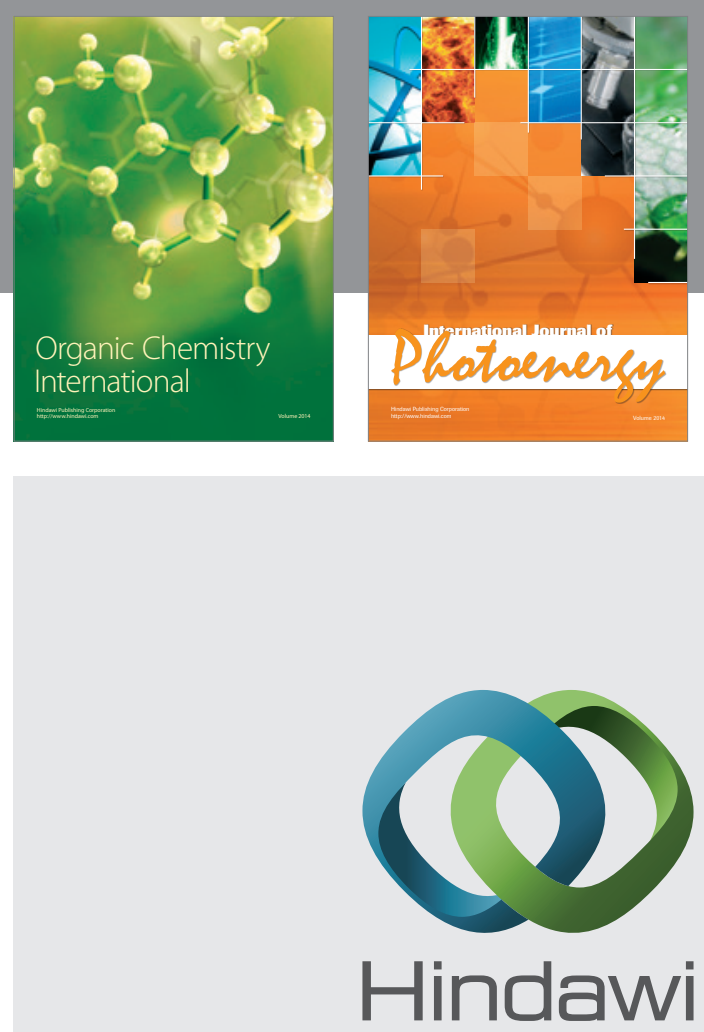

Submit your manuscripts at

http://www.hindawi.com

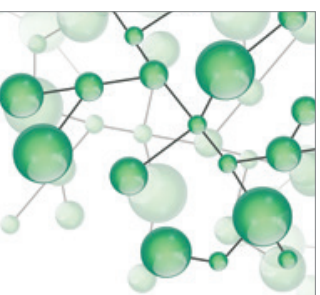

International Journal of

Inorganic Chemistry

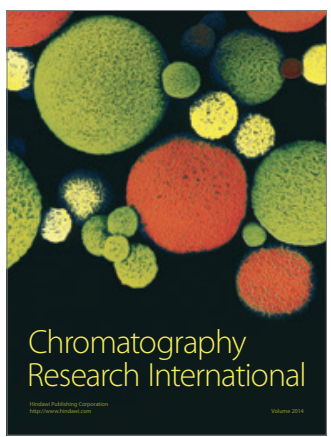

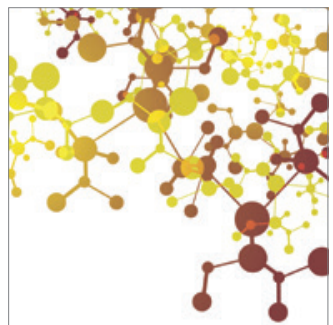

Applied Chemistry
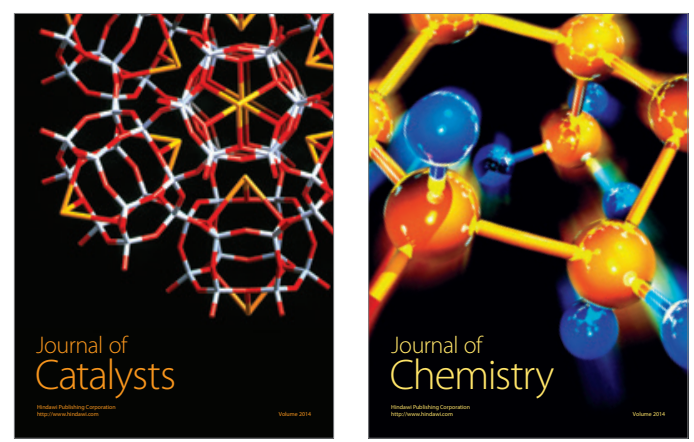
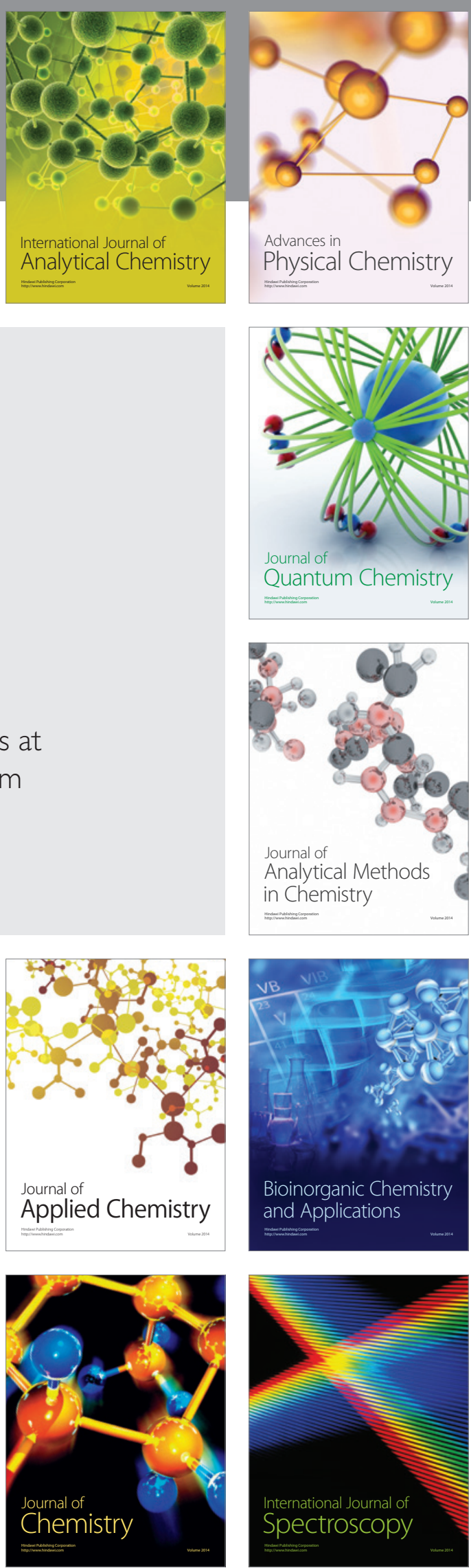